\title{
Deconvoluting the Molecular Control of Binding and Signaling at the Amylin 3 Receptor: RAMP3 Alters Signal Propagation through Extracellular Loops of the Calcitonin Receptor
}

Vi Pham, ${ }^{\dagger, \#}$ Yue Zhu, ${ }^{\ddagger, \S, \#}$ Emma Dal Maso, ${ }^{\dagger, \#}$ Christopher A. Reynolds, "Giuseppe Deganutti," Silvia Atanasio, ${ }^{\|}$Caroline A. Hick, ${ }^{\dagger}$ Dehua Yang, ${ }^{\ddagger}$ Arthur Christopoulos, ${ }^{\dagger}$ Debbie L. Hay, ${ }^{\perp}(\mathbb{0}$ Sebastian G. B. Furness, ${ }^{\dagger}$ Ming-Wei Wang, ${ }^{*},+,{ }^{+}$Denise Wootten, ${ }^{*}{ }^{\dagger}$ and Patrick M. Sexton ${ }^{*}+\odot$

${ }^{\dagger}$ Drug Discovery Biology, Monash Institute of Pharmaceutical Sciences, Monash University, Parkville 3052, Victoria, Australia

${ }^{\ddagger}$ The National Center for Drug Screening and CAS Key Laboratory of Receptor Research, Shanghai Institute of Materia Medica, Chinese Academy of Sciences, Shanghai 201203, China

${ }^{\S}$ University of Chinese Academy of Sciences, 19A Yuquan Road, Beijing 100049, China

"School of Biological Sciences, University of Essex, Wivenhoe Park, Colchester CO4 3SQ U.K.

${ }^{\perp}$ The University of Auckland, School of Biological Sciences, 3 Symonds Street, Auckland 1142, New Zealand

Supporting Information

ABSTRACT: Amylin is coexpressed with insulin in pancreatic islet $\beta$ cells and has potent effects on gastric emptying and food intake. The effect of amylin on satiation has been postulated to involve $\mathrm{AMY}_{3}$ receptors $\left(\mathrm{AMY}_{3} \mathrm{R}\right)$ that are heteromers of the calcitonin receptor (CTR) and receptor activity-modifying protein 3 (RAMP3). Understanding the molecular control of signaling through the $\mathrm{AMY}_{3} \mathrm{R}$ is thus important for peptide drug targeting of this receptor. We have previously used alanine scanning mutagenesis to study the contribution of the extracellular surface of the CTR to binding and signaling initiated by calcitonin (CT) and related peptides (Dal Maso, E., et al. (2019) The molecular control of calcitonin receptor signaling. ACS Pharmacol. Transl. Sci. 2, 31-51). That work revealed ligand- and pathway-specific effects of mutation, with extracellular loops (ECLs) 2

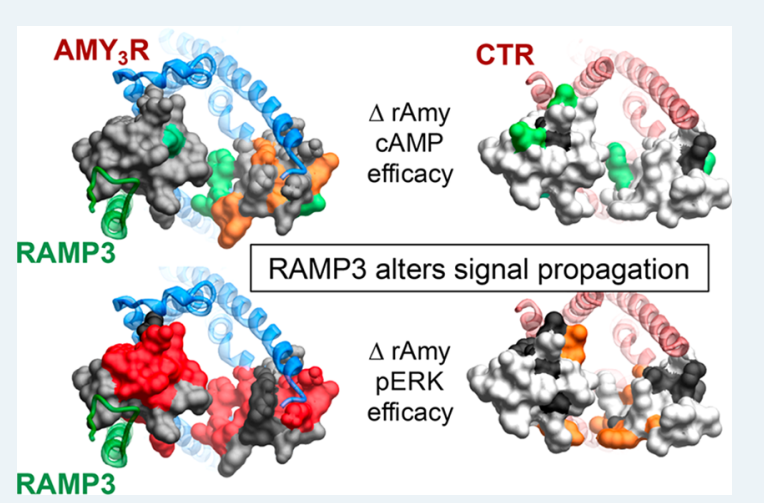
and 3 particularly important in the distinct propagation of signaling mediated by individual peptides. In the current study, we have used equivalent alanine scanning of ECL2 and ECL3 of the CTR in the context of coexpression with RAMP3 to form $\mathrm{AMY}_{3} \mathrm{Rs}$, to examine functional affinity and efficacy of peptides in cAMP accumulation and extracellular signal-regulated kinase (ERK) phosphorylation ( $\mathrm{pERK}$ ). The effect of mutation was determined on representatives of the three major distinct classes of CT peptide, salmon CT (sCT), human CT (hCT), and porcine CT (pCT), as well as rat amylin (rAmy) or human $\alpha$-CGRP (calcitonin gene-related peptide, hCGRP) whose potency is enhanced by RAMP interaction. We demonstrate that the dynamic nature of CTR ECL2 and ECL3 in propagation of signaling is fundamentally altered when complexed with RAMP3 to form the $\mathrm{AMY}_{3} \mathrm{R}$, despite only having predicted direct interactions with ECL2. Moreover, the work shows that the role of these loops in receptor signaling is highly peptide dependent, illustrating that even subtle changes to peptide sequence may change signaling output downstream of the receptor.

KEYWORDS: amylin receptor, calcitonin receptor, receptor activity-modifying protein, $G$ protein-coupled receptor, receptor structure-function, cell signaling

\section{INTRODUCTION}

G protein-coupled receptors (GPCRs) are the largest superfamily of cell surface protein conduits of extracellular chemical information to the inside of cells. ${ }^{1}$ As such, understanding the molecular basis of how these extracellular signals are conformationally propagated through the GPCR to recruit and activate signal transducers is critically important to development of novel therapeutics that regulate this process. Moreover, GPCRs can recruit multiple different transducers and other regulatory proteins and this can be altered in a ligand-specific manner, leading to biased agonists that hold promise as precision medicines to treat various diseases. ${ }^{2}$

Class B1 GPCRs are an important subfamily for key physiological peptides that regulate diverse functions including energy homeostasis, bone metabolism, immune function, lymph and vascular formation, and the control of vascular tone. ${ }^{3}$ The calcitonin receptor (CTR) is a broadly expressed

Received: February 7, 2019

Published: March 18, 2019 
class B1 GPCR that is most recognized for its expression in bone resorbing osteoclasts, and its role in bone metabolism. ${ }^{4}$ However, CTRs also interact with a family of 3 receptor activity-modifying proteins (RAMPs) to yield high affinity receptors for amylin and calcitonin gene-related peptide (CGRP). ${ }^{5}$ These are termed $\mathrm{AMY}_{1}, \mathrm{AMY}_{2}$, and $\mathrm{AMY}_{3}$ receptors according to the interacting RAMP, i.e., RAMP1, RAMP2, and RAMP3, respectively. In addition to modifying the binding specificity of the CT family of receptors, a major consequence of GPCR-RAMP interaction is alteration to the signaling profile of the receptor, ${ }^{6}$ and this has been observed for the AMY receptors relative to CTR alone. ${ }^{7}$

Amylin is coexpressed with insulin in pancreatic islet $\beta$-cells and has potent effects on gastric emptying and food intake. ${ }^{8}$ Pramlintide, a nonamyloidogenic analogue of human amylin is approved for the treatment of type 1 diabetes in combination with insulin. ${ }^{8}$ However, amylin analogues also promote satiation and can lead to significant weight loss in overweight patients, and cause marked weight loss in animal models of obesity when coadministered with other agents that promote weight loss, such as glucagon-like peptide-1 (GLP-1) receptor agonists or leptin. ${ }^{9,18}$ Accordingly, there is significant interest in the development of new amylin analogues to better treat obesity. ${ }^{8}$

The amylin effect on satiation has been localized to amylin receptors in the area postrema and has been proposed to involve the $\mathrm{AMY}_{3} \mathrm{R}$ subtype (CTR:RAMP3 heteromer), ${ }^{11}$ although all three RAMPs are present in the area postrema. ${ }^{8}$ Understanding the molecular control of signaling through the $\mathrm{AMY}_{3} \mathrm{R}$ is thus crucial for peptide drug targeting of this receptor.

Recent advances in cryo-electron microscopy have allowed determination of the structures of active state class B GPCRs in complex with peptide agonists and the canonical Gs protein, $^{12-15}$ including complexes of the $\mathrm{CTR}^{12,16}$ and the CGRP receptor. ${ }^{15}$ The latter is a hetromer of the related calcitonin receptor-like receptor (CLR) and RAMP1. These structures have allowed identification of the peptide binding domain within the receptor core and serve as a template for 3dimensional (3D) mapping of the effect of mutation on receptor function. Importantly, the solution of the CGRP receptor (CGRPR) complex revealed a novel interface for RAMP interaction with transmembrane helices 4 and 5 that extended to parts of extracellular loop (ECL) $2,^{15}$ and allows for the first-time structure-based modeling of related RAMPclass B GPCR complexes.

We have previously used alanine scanning mutagenesis to study the contribution of the extracellular surface of the CTR to binding and signaling initiated by $\mathrm{CT}$ and related peptides. ${ }^{16,17}$ This work revealed ligand- and pathway-specific effects of mutation, with ECLs 2 and 3 particularly important in the distinct propagation of signaling mediated by individual peptides. ${ }^{17}$ In the current study, we have used equivalent alanine scanning of ECL2 and ECL3 of the CTR in the context of coexpression with RAMP3 to form $\mathrm{AMY}_{3} \mathrm{Rs}$, in order to examine functional affinity and efficacy of peptides in cAMP accumulation and extracellular signal-regulated kinase (ERK) phosphorylation ( $\mathrm{pERK}$ ). The effect of mutation was determined on representatives of the three major distinct classes of CT peptide, salmon CT (sCT), human CT (hCT), and porcine CT (pCT), as well as rat amylin (rAmy) or human $\alpha$-CGRP (hCGRP) whose potency is enhanced by RAMP interaction. The work illustrates that interaction with RAMP3 dynamically alters how ECL2 and ECL3 contribute to propagation of signaling through the CTR.

\section{RESULTS AND DISCUSSION}

Importance of ECL2 and ECL3 in the Control of $A M Y_{3} R$ Function. To gain insight into the role of RAMP3 in the $\mathrm{AMY}_{3} \mathrm{R}$ phenotype we performed alanine scanning mutagenesis on CTR ECL2 (I279-I300) and ECL3 (F356M376) that play important roles in peptide binding and propagation of signaling at the CTR in the absence of RAMPs. ${ }^{17}$ Each of these mutants was analyzed for their effect on cell surface expression (Figure 1), binding affinity in
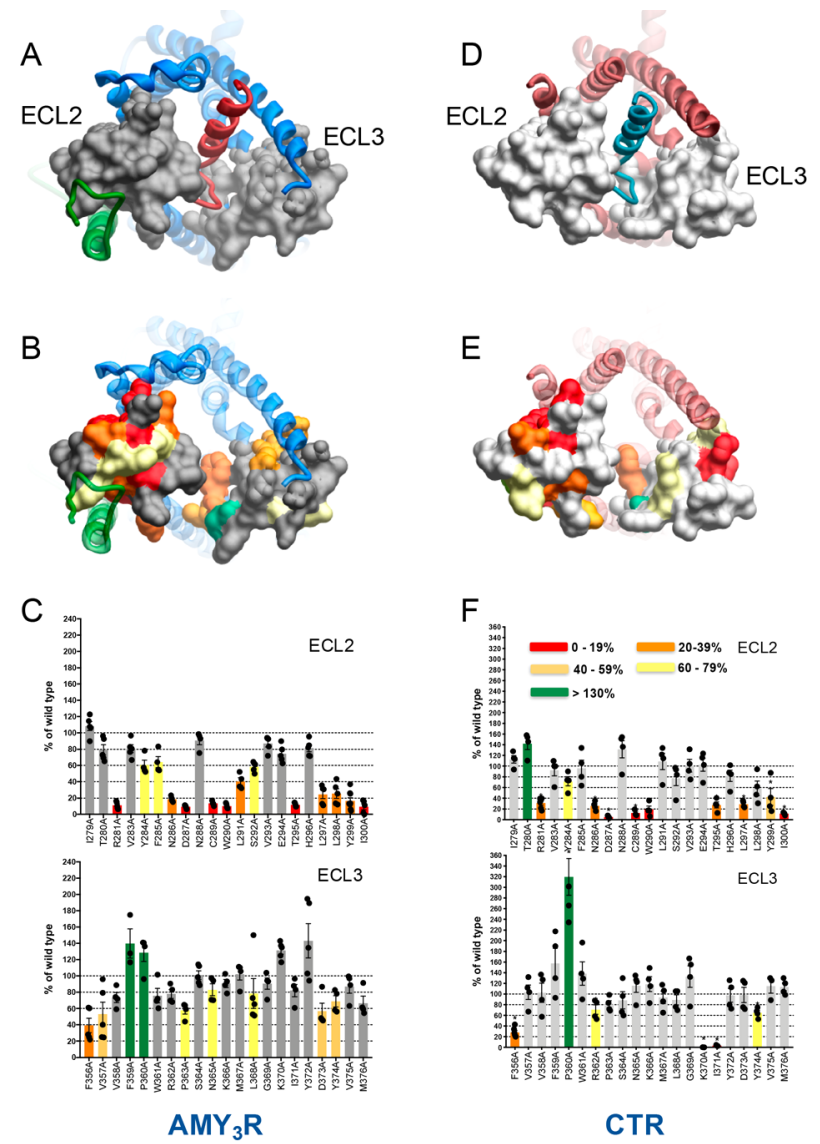

Figure 1. Effect of alanine mutation on the cell surface expression of the $\mathrm{AMY}_{3} \mathrm{R}$ and CTR. (A-C) $\mathrm{AMY}_{3} \mathrm{R} ;(\mathrm{D}-\mathrm{F}) \mathrm{CTR}$ (extracted from Dal Maso et al, $2018^{17}$ ). (A, D) Top view of the active, sCT-bound, $\mathrm{AMY}_{3} \mathrm{R}(\mathrm{A})$ or CTR (6NIY) (D) model with the extracellular surface subject to alanine scanning depicted in gray (A) or off-white (D) (combined surface/cpk representation). The rest of the protein complex is shown in ribbon representation. CTR (blue, $\mathrm{AMY}_{3} \mathrm{R}$; dark red, CTR), sCT peptide (dark red, $\mathrm{AMY}_{3} \mathrm{R}$; aquamarine, CTR), RAMP3 (green). The receptor ECD is omitted for clarity. (B, E) Map of the effect of mutation on cell surface receptor expression colored according to the legend in panel F. (C, F) Effect of alanine mutation of ECL2 and ECL3 on CTR expression monitored by FACS of anti-cMyc antibody binding to the N-terminal c-Myc epitope on the receptor. Data are normalized to the expression of the wild-type (WT) receptor (100\%). Significant differences in the level of cell surface expression were determined by one-way ANOVA followed by Dunnett's post-test comparison to the WT. $P<0.05$ was used to denote significance, and colored according to the magnitude of change. Individual values (separate experiments) are shown within the bars. 


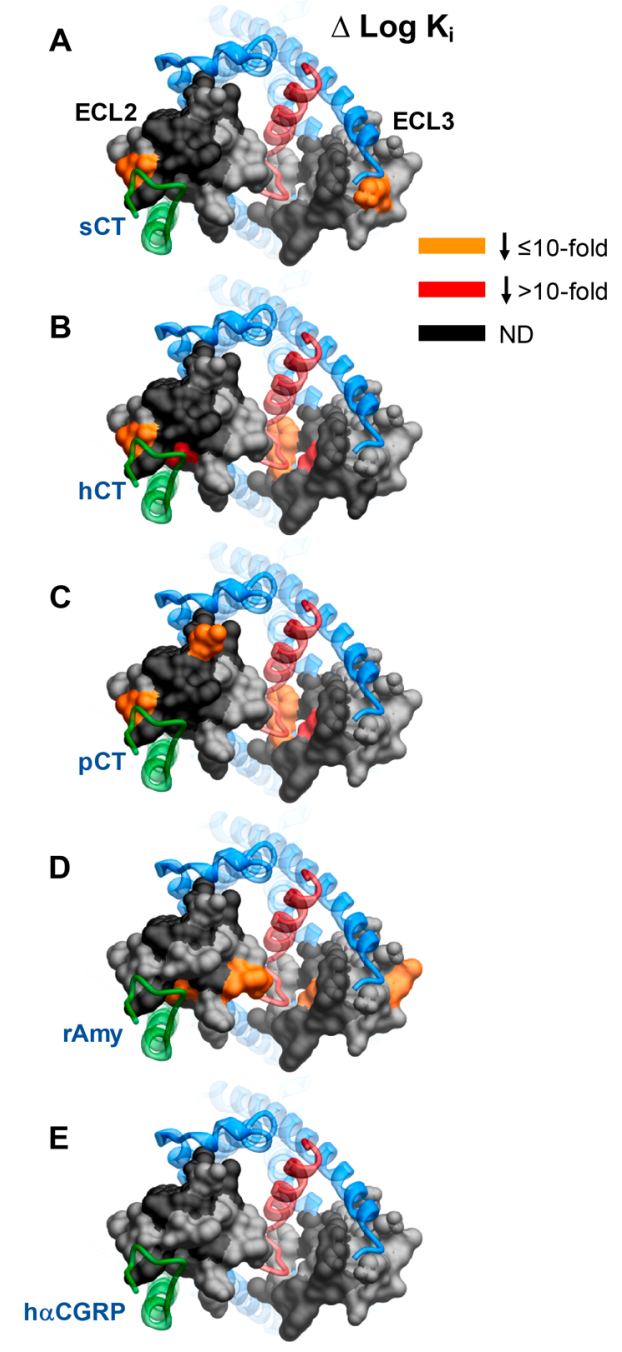

Figure 2. Identification of key amino acids of $\mathrm{AMY}_{3} \mathrm{R}$ ECL2 and ECL3 for peptide binding affinity $\left(\log K_{i}\right)$. (A) sCT; (B) hCT; (C) pCT; (D) rAmy; (E) hCGRP. Mutations that significantly decreased peptide affinity in radioligand competition assay are colored dark orange ( $\leq 10$-fold effect) or red ( $>10$-fold effect), with mutated amino acids without significant alteration to $\log K_{i}$ colored gray. Amino acid mutations where there was an insufficiently robust functional effect to quantify by radioligand competition binding are depicted in black. The receptor ECD is not shown for clarity, with the CTR TM bundle in blue ribbon and RAMP3 in green ribbon. Quantitative data are reported in Table 1.

competitive radioligand binding assays (Figure 2, Table 1, Figures S1-S6), and functional response (pERK and cAMP accumulation) for each peptide (Figures 3-8, Figures S7-S16, Tables 2-5). A homology model of the $\mathrm{AMY}_{3} \mathrm{R}$ complex was built from deposited structures of the CTR $\left(6 \mathrm{NIY}^{16}\right)$ and CGRPR (6E3Y; ${ }^{15}$ for initial positioning of RAMP3) active complexes and subjected to a short molecular dynamics (MD) simulation $(200 \mathrm{~ns})$ to resolve energetically unfavorable interactions. This model was used to map effects of mutation on the $\mathrm{AMY}_{3} \mathrm{R}$ and to enable comparison to the effects of previously published equivalent mutations on the CTR, ${ }^{16,17}$ mapped onto the recently published $3.3 \AA$ structure (6NIY) that included ECL2 and ECL3 side chains ${ }^{16}$ (Figures 9-12).
Receptor Expression. $\mathrm{AMY}_{3} \mathrm{Rs}$ were expressed using a Flp-In bicistronic vector of N-terminally tagged cMyc-CTR and RAMP3, where the RAMP is overexpressed relative to the CTR, and stable cell lines of each mutant receptor generated by isogenic integration into Flp-In CV-1 cells. Anti-cMyc antibody binding to the CTR was measured by FACS as a marker of the cell surface expression of the $\mathrm{AMY}_{3} \mathrm{R}$ (Figure 1).

There was a marked decrease in surface expression of CTR in the $\mathrm{AMY}_{3} \mathrm{R}$ for the R281A, N286A, D287A, C289A, W290A, T295A, L297A, L298A, Y299A, and I300A mutants within ECL2, with decreased expression to a lesser extent also seen with Y284A, F285A, L291A, and S292A mutants within this loop (Figure 1B,C). In general, the pattern of effect was similar to that seen with the CTR expressed alone ${ }^{17}$ (Figure $1 \mathrm{E}, \mathrm{F})$ although greater loss of expression was seen for the L291A and S292A mutants when the receptor was coexpressed with RAMP3. Alanine mutation within ECL3 had less overall impact relative to ECL2, with moderate, significant, decreases in expression for F356A, V357A, P363A, N365A, L286A, $\mathrm{D} 373 \mathrm{~A}$, and $\mathrm{Y} 374 \mathrm{~A}$, and increases for F359A and P360A (Figure 1B,C). The lack of effect of K370A and I371A mutation of the $\mathrm{AMY}_{3} \mathrm{R}$ was in marked contrast to the effect of these mutants in the absence of RAMP3, where there was almost undetectable levels of CTR expression, and very high levels of expression observed for the P360A mutation (Figure $1 \mathrm{E}, \mathrm{F})$, although overall there was only limited impact of mutation in ECL3. Although RAMP3 is overexpressed relative to CTR in the bicistronic vector, it is likely that both $\mathrm{AMY}_{3} \mathrm{R}$ and CTR alone forms of the receptor are formed. Nonetheless, the marked difference in surface expression of the K370A and I371A mutants ( $100 \%$ versus $<5 \%$ for $\mathrm{AMY}_{3} \mathrm{R}$ and CTR, respectively) supports that the cocomplex with RAMP3 accounts for the majority of receptors in the CV-1 cells.

Peptide Affinity (Competition Binding). To specifically examine the impact of mutation on the affinity of peptide ligands for the $\mathrm{AMY}_{3} \mathrm{R}$, radioligand competition binding studies were performed with ${ }^{125} \mathrm{I}$-rAmylin. We have previously demonstrated that there is no measurable specific binding to CTR alone at the concentrations of radioligand used. ${ }^{18}$ No specific binding was detected for the R281A, Y284A, N286A, D287A, C289A, W290A, L291A, T295A and I300A mutants in ECL2, or for the V357A, P360A, W361A R362A, P363A, L368A, D373A, and M376A mutants in ECL3 (Table 1, Figure 2). Many of these within ECL2 also had low cell surface expression (Figure 1C). In contrast, there was moderate to strong cell surface expression of most ECL3 mutants indicating that the loss of binding was likely due to alterations to binding affinity of the radioligand. Of those mutants with a robust specific binding window, there was a subset that exhibited loss of affinity, in a peptide specific manner (Table 1, Figure 2, Figures S1-S6). hCGRP was least impacted, with no significant change in observed affinity (Figure S1E). There was a selective loss of rAmy affinity for the E294A and G369A mutants (Figure S1D), of hCT for the T280A, L298A, and S364A mutants (Figure S1B), of sCT for the K366A mutant, and $\mathrm{pCT}$ for the N288A mutant (Figures S1A and S1C, respectively). F285A and Y299A displayed a selective loss of affinity for CT peptides with no significant effect on rAmy or hCGRP. Similarly, there was loss of affinity for all CT peptides for the V358A and F359A mutants; rAmy affinity was also decreased at V358A (Table 1, Figures S1A-D). There was selective loss of affinity for $\mathrm{sCT}$ and $\mathrm{pCT}$ at the V283A mutant, hCT, pCT, and rAmy at the L297A and Y372A mutants, and 
Table 1. Effect of Single Alanine Mutation in $\mathrm{AMY}_{3} \mathrm{R}$ ECL2 or ECL3 on Binding Affinity $\left(\log K_{i}\right)$ of Peptides Derived from Competition Binding Isotherms ${ }^{a}$

\begin{tabular}{|c|c|c|c|c|c|c|c|c|c|c|c|c|c|c|c|}
\hline & SCT & & & hCT & & & pCT & & & Amy & & & CGRP & & \\
\hline & Mean & S.E.M. & $\mathbf{N}$ & Mean & S.E.M. & $\mathrm{N}$ & Mean & S.E.M. & $\mathbf{N}$ & Mean & S.E.M. & $\mathbf{N}$ & Mean & S.E.M. & $\mathbf{N}$ \\
\hline WT & -9.70 & 0.07 & 16 & -7.01 & 0.08 & 17 & \begin{tabular}{|l|}
-7.83 \\
\end{tabular} & 0.06 & 17 & $\begin{array}{l}-8.75 \\
\end{array}$ & 0.06 & 19 & -6.88 & 0.07 & 17 \\
\hline 1279A & \begin{tabular}{|l|}
-9.26 \\
\end{tabular} & 0.17 & 5 & -7.17 & 0.16 & 5 & \begin{tabular}{|l|}
-8.02 \\
\end{tabular} & 0.10 & 5 & \begin{tabular}{|l|}
-8.83 \\
\end{tabular} & 0.09 & 5 & -6.92 & 0.12 & 5 \\
\hline T280A & -9.13 & 0.22 & 3 & -6.13 & 0.35 & 3 & -7.73 & 0.22 & 3 & -8.52 & 0.17 & 4 & -6.63 & 0.26 & 4 \\
\hline \multicolumn{16}{|l|}{ R281A } \\
\hline V283A & -9.14 & 0.14 & 5 & -6.92 & 0.17 & 5 & $\mid-7.15$ & 0.17 & 5 & -8.40 & 0.13 & 5 & -7.00 & 0.10 & 5 \\
\hline \multicolumn{16}{|l|}{ Y284A } \\
\hline F285A & ND & & & ND & & & ND & & & -8.68 & 0.20 & 3 & -6.87 & 0.15 & 3 \\
\hline \multicolumn{16}{|l|}{ N286A } \\
\hline \multicolumn{16}{|l|}{ D287A } \\
\hline N288A & -9.45 & 0.25 & 5 & -6.46 & 0.24 & 5 & -7.28 & 0.12 & 5 & -8.51 & 0.11 & 5 & -6.90 & 0.16 & 5 \\
\hline \multicolumn{16}{|l|}{ C289A } \\
\hline \multicolumn{16}{|l|}{ W290A } \\
\hline \multicolumn{16}{|l|}{ L291 } \\
\hline S292A & -9.74 & 0.15 & 4 & -6.65 & 0.12 & 3 & -8.08 & 0.13 & 5 & -8.37 & 0.11 & 5 & -6.59 & 0.12 & 5 \\
\hline V293A & -9.34 & 0.17 & 5 & -6.94 & 0.14 & 5 & -7.40 & 0.24 & 4 & -8.82 & 0.08 & 5 & -7.39 & 0.17 & 5 \\
\hline E294A & -9.74 & 0.12 & 5 & -6.88 & 0.22 & 5 & -7.78 & 0.17 & 5 & -8.20 & 0.11 & 5 & -6.80 & 0.16 & 4 \\
\hline \multicolumn{16}{|l|}{ T295A } \\
\hline H296A & -9.59 & 0.14 & 4 & -6.91 & 0.13 & 4 & -7.45 & 0.13 & 5 & -8.78 & 0.13 & 4 & -6.70 & 0.13 & 5 \\
\hline L297A & -9.58 & 0.27 & 3 & $<-6$ & & 3 & ND & & & -8.09 & 0.19 & 4 & -6.82 & 0.21 & 4 \\
\hline L298A & -9.51 & 0.14 & 5 & -6.11 & 0.19 & 5 & -7.48 & 0.10 & 5 & -8.94 & 0.10 & 5 & -6.64 & 0.16 & 5 \\
\hline Y299A & ND & & & ND & & & ND & & & -8.26 & 0.24 & 4 & -6.75 & 0.27 & 3 \\
\hline \multicolumn{16}{|l|}{$1300 \mathrm{~A}$} \\
\hline F356A & -9.63 & 0.11 & 5 & -6.34 & 0.11 & 5 & -7.35 & 0.10 & 5 & -8.82 & 0.06 & 5 & -7.16 & 0.08 & 5 \\
\hline \multicolumn{16}{|l|}{ V357A } \\
\hline V358A & ND & & & ND & & & -7.11 & 0.20 & 3 & -8.01 & 0.17 & 5 & -6.83 & 0.21 & 4 \\
\hline F359A & ND & & & ND & & & -6.84 & 0.26 & 3 & -8.36 & 0.21 & 5 & -6.93 & 0.16 & 3 \\
\hline \multicolumn{16}{|l|}{ P360A } \\
\hline \multicolumn{16}{|l|}{ W361A } \\
\hline \multicolumn{16}{|l|}{ R362A } \\
\hline \multicolumn{16}{|l|}{ P363A } \\
\hline S364A & -9.37 & 0.17 & & ND & & & -7.46 & 0.11 & 4 & -8.80 & 0.15 & 4 & -6.91 & 0.15 & 4 \\
\hline N365A & -9.38 & 0.11 & 3 & -7.07 & 0.21 & 3 & -7.99 & 0.18 & 4 & -8.94 & 0.12 & 4 & -7.04 & 0.17 & 5 \\
\hline K366A & -8.79 & 0.18 & 5 & -6.93 & 0.13 & 4 & -7.57 & 0.12 & 5 & -8.85 & 0.20 & 5 & -7.00 & 0.14 & 5 \\
\hline M367A & -9.46 & 0.25 & & ND & & & -7.05 & 0.14 & 5 & -8.25 & 0.21 & 4 & -6.94 & 0.14 & 4 \\
\hline \multicolumn{16}{|l|}{ L368A } \\
\hline G369A & -9.95 & 0.20 & 4 & -6.87 & 0.16 & 4 & -7.60 & 0.10 & 4 & -8.02 & 0.14 & 4 & -7.07 & 0.18 & 4 \\
\hline K370A & -9.66 & 0.12 & 5 & -7.05 & 0.14 & 5 & -7.61 & 0.10 & 5 & -8.93 & 0.12 & 5 & -6.99 & 0.12 & 5 \\
\hline I371A & -9.64 & 0.13 & 4 & -7.06 & 0.19 & 4 & -7.80 & 0.13 & 4 & -8.47 & 0.12 & 4 & -6.83 & 0.16 & 4 \\
\hline Y372A & -9.14 & 0.16 & & $<-6$ & & 4 & -6.74 & 0.15 & 5 & -7.92 & 0.10 & 5 & -7.21 & 0.16 & 4 \\
\hline \multicolumn{16}{|l|}{ D373A } \\
\hline Y374A & -9.63 & 0.18 & 3 & -6.87 & 0.21 & 4 & -7.54 & 0.12 & 4 & -8.69 & 0.11 & 5 & -6.98 & 0.15 & 5 \\
\hline V375A & -9.49 & 0.15 & 5 & -7.03 & 0.10 & 5 & -7.54 & 0.08 & 5 & -8.92 & 0.11 & 5 & -6.99 & 0.12 & 5 \\
\hline
\end{tabular}

${ }^{a} \log K_{i}$ values were derived for each ligand and mutant receptor from analysis of either homologous (rAmy) or heterologous (sCT, hCT, pCT, h $\alpha$ CGRP) competition of ${ }^{125}$ I-rAmy binding. Mean, S.E.M. and the individual experimental " $n$ " values are reported. Significance of changes in log $K_{i}$ of each ligand was determined by comparison of mutant receptors to WT values by a one-way ANOVA and Dunnett's post-test ( $p<0.05$ denoted by bold coloured entries. Orange, significant decrease $\leq 10$-fold; red, significant decrease $>10$-fold). Gray shading indicates mutants where robust radioligand binding was not detected. N.D. indicates that no value could be derived due to lack of robust competition and high data variance.

of hCT and pCT at the F356A and M367A mutants (Table 1, Figures S1A-D). The effect of mutations within ECL2 appeared to coincide with residues known to contribute to packing of ECL2 in $\mathrm{CTR}^{16}$ or were in close proximity to the predicted RAMP3 interface (Figure 2). In contrast, the effect of most mutations within ECL3 were consistent with potential peptide binding interfaces and differential strength of interaction for individual peptides (Figure 2).

Peptide Functional Affinity. For each peptide, concentration-response isotherms were established in assays of cAMP accumulation and pERK1/2 (Figures S7-S16), and data were analyzed by operational modeling to derive estimates of functional affinity $\left(\log K_{\mathrm{A}}\right.$ ) (Figures 3 and 4, Tables 2 and 3) and efficacy $(\log \tau)$ for each pathway; the latter were corrected for differences in cell surface expression (Figures 6 and 7, Tables 4 and 5).

There was a marked peptide dependence in the effect of mutation on cAMP functional affinity, with the greatest impact on hCT and pCT across both ECL2 and ECL3 (Figure 3, Table 2). hCGRP functional affinity was minimally affected by mutation with significant loss of affinity for L368A, but no detectable response (ND) for C289A, P363A, and D373A (Figures 3A,B; and 5E). Similarly, there was only limited effect on rAmy functional affinity, with loss of affinity for W290A and L291A in ECL2 and F359A, P363A, L368A, and D373A in ECL3 (Figures 3D,I; 5D). For sCT, only V357A in ECL3 altered affinity, with greater impact in ECL2 with decreased functional affinity for D287A, W290A, S292A and I300A (Figures 3A,B; 5A). In distinction to the limited effects of mutations on responses to these peptides, there was very marked, extended impact on hCT and pCT (Figures 3B,C,G,H; 5B,C). Within ECL2 and the TM5 proximal segment of ECL3, there was very similar impact on cAMP functional affinity for both peptides with attenuated affinity for R281A (ND for hCT), N286A, D297A, C289A, W290A (ND for hCT), L291A, S292A, T295A, and L297A-I300A within ECL2, and F359A-P363A in ECL3, with the exception of L297A, L298A, and V358A that had no significant effect on pCT affinity. Similarly, there was parallel loss of affinity for Y372A, D373A, and M376A for both peptides. Nonetheless, divergent effects were seen for K366A, M367A, and V375A (selective increased affinity for pCT), and L368A (selective 

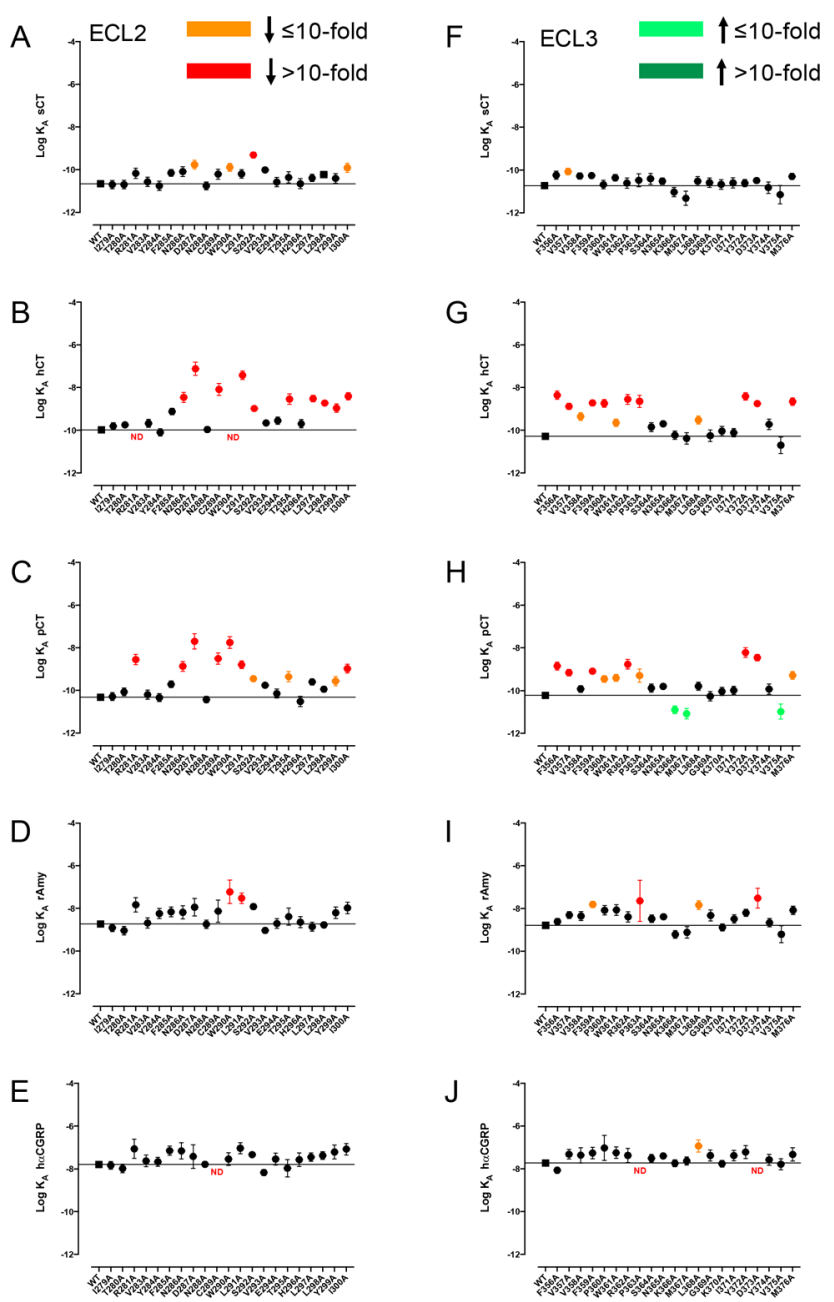

Figure 3. Alanine mutation of ECL2 and ECL3 of $\mathrm{AMY}_{3} \mathrm{R}$ alters cAMP functional affinity $\left(\log K_{\mathrm{A}}\right)$ in a peptide-specific manner. Functional affinities derived from operational fitting of concentration-response curves in cAMP accumulation for alanine mutation of ECL2 (A-E) and ECL3 (F-J) are displayed as $\log K_{\mathrm{A}}$. Significance of changes was established by comparison of the WT to the other receptor mutants following one-way ANOVA and Dunnett's post-test with $P<0.05$ accepted as significant. Mutants that gave significant reductions between 3 - and 10-fold are colored orange, and those with reductions greater than 10 -fold are colored red. Mutants giving significant increases in $\log K_{\mathrm{A}}$ are colored green. Where data were insufficiently robust to derive a reliable value for $\log K_{\mathrm{A}}$ no symbol is shown (ND). Quantitative data are reported in Table 2.

decreased affinity for hCT) (Figures 3B,C,G,H; 5B,C; Table 2).

In contrast to the dramatic effect on cAMP functional affinity, there was no significant effect on measured pERK functional affinity for any of the peptides (Figures 4 and 5, Table 3). However, robust responses were not seen for the following mutants and peptides; R281A (hCT), D287A (hCT, pCT, hCGRP), C289A (hCT, rAmy), W290A (hCGRP), L291A (hCT, hCGRP), L298A, I300A, P360A (hCGRP), R362A, P363A (rAmy, hCGRP), K370A (rAmy), I371A (hCT, rAmy, hCGRP), D373A, V375A, and M376A (hCGRP) and thus the nature of the loss of response could not be determined.

These data revealed marked differences in how ECL2 and ECL3 contribute to functional affinity across the two pathways at the $\mathrm{AMY}_{3} \mathrm{R}$ (Figure 5). The most notable differences were
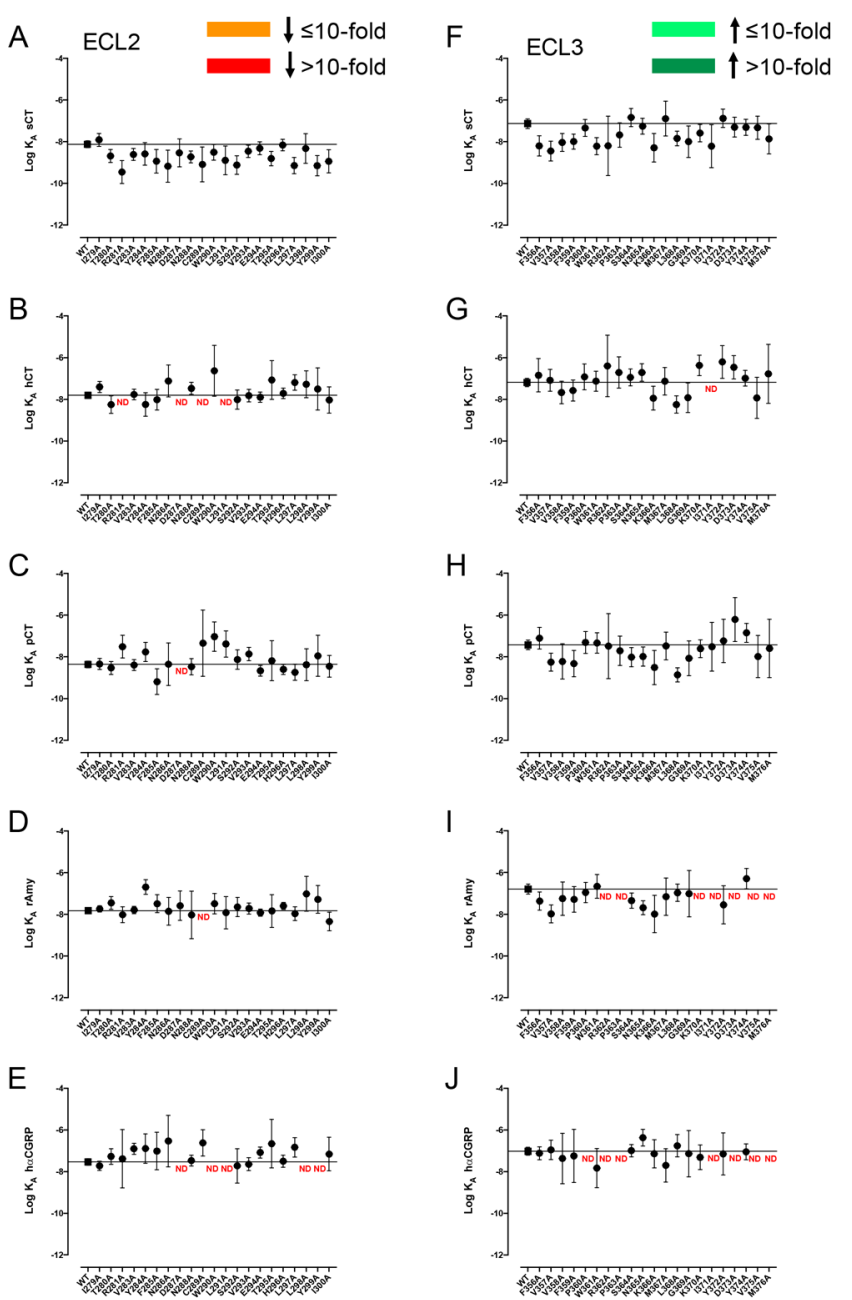

Figure 4. Alanine mutation of ECL2 and ECL3 of $\mathrm{AMY}_{3} \mathrm{R}$ has limited effect on pERK functional affinity $\left(\log K_{\mathrm{A}}\right)$. Functional affinities derived from operational fitting of concentration-response curves in ERK phosphorylation for alanine mutation of ECL2 (A-E) and ECL3 (F-J) are displayed as $\log K_{\mathrm{A}}$. No significant changes in $\log K_{\mathrm{A}}$ from WT were seen for receptor mutants following one-way ANOVA and Dunnett's post-test with $P<0.05$ accepted as significant. Where data were insufficiently robust to derive a reliable value for $\log K_{\mathrm{A}}$ no symbol is shown (ND). Quantitative data are reported in Table 3.

seen for hCT and pCT for which there was broad importance of the amino acids in the core of ECL2, and peptide proximal residues of ECL3, in cAMP but not $\mathrm{PERK}$ functional affinity (Figure 5B,C versus Figure 5G,H). Alanine mutants that selectively increased cAMP functional affinity for pCT clustered away from the peptide binding site and were located on the periphery of the receptor transmembrane domain. This region would be predicted to interact with the membrane bilayer, suggesting that these candidate receptor-membrane interactions constrain the receptor in a way that limits pCT functional affinity when RAMP3 is present, as the effect of mutation was not seen with mutants of CTR alone ${ }^{17}$ (Figure $6 \mathrm{C}$ versus Figure $6 \mathrm{H})$. For the other peptides, there was limited effect of loop mutation on functional affinity for either pathway, with the quantifiable effects primarily occurring within residues involved in packing of the ECL2 in the active structures (Figure 5). While no quantifiable effect was seen on pERK functional affinity, there was a cluster of residues at the apex of ECL3 that adversely affected rAmy and hCGRP 
Table 2. Effect of Single Alanine Mutation in $\mathrm{AMY}_{3} \mathrm{R}$ ECL2 or ECL3 on cAMP Functional Affinity (log $\left.K_{\mathrm{A}}\right)$ of Peptides ${ }^{a}$

\begin{tabular}{|c|c|c|c|c|c|c|c|c|c|c|c|c|c|c|c|}
\hline & CT & & & hCT & & & $\mathrm{T}$ & & & my & & & GRP & & \\
\hline & Mean & S.E.M. & $\mathbf{N}$ & Mean & S.E.M. & $\mathbf{N}$ & Mean & S.E.M. & $\mathbf{N}$ & Mean & S.E.M. & $\mathbf{N}$ & Mean & S.E.M. & $\mathbf{N}$ \\
\hline WT (ECL2) & -10.66 & 0.07 & 26 & -9.99 & 0.06 & 23 & -10.32 & 0.06 & 26 & -8.73 & 0.06 & 26 & -7.79 & 0.05 & 34 \\
\hline 1279A & -10.70 & 0.20 & 4 & -9.81 & 0.17 & 4 & -10.29 & 0.18 & 4 & -8.91 & 0.18 & 4 & -7.83 & 0.18 & 4 \\
\hline T280A & -10.70 & 0.20 & 4 & -9.75 & 0.09 & 11 & -10.07 & 0.18 & 4 & -9.04 & 0.20 & 4 & -7.98 & 0.20 & 4 \\
\hline R281A & -10.17 & 0.24 & $4 \mathrm{I}$ & ND & & 4 & -8.56 & 0.24 & 4 & -7.83 & 0.34 & 4 & -7.06 & 0.45 & 7 \\
\hline V283A & -10.57 & 0.22 & 4 & -9.68 & 0.18 & 4 & -10.20 & 0.22 & 4 & -8.68 & 0.24 & 4 & -7.63 & 0.27 & 4 \\
\hline Y284A & -10.76 & 0.22 & 4 & -10.10 & 0.17 & 4 & -10.34 & 0.19 & 4 & -8.24 & 0.24 & 4 & -7.67 & 0.21 & 4 \\
\hline F285A & -10.15 & 0.16 & 4 & -9.12 & 0.15 & 5 & -9.71 & 0.15 & 4 & -8.16 & 0.23 & 4 & -7.15 & 0.22 & 4 \\
\hline N286A & -10.09 & 0.23 & 4 & -8.46 & 0.23 & 5 & -8.87 & 0.23 & 4 & -8.19 & 0.31 & 4 & -7.16 & 0.38 & 4 \\
\hline D287A & -9.76 & 0.21 & 4 & -7.12 & 0.31 & 5 & -7.70 & 0.36 & 4 & -7.95 & 0.41 & 7 & -7.42 & 0.55 & 6 \\
\hline N288A & -10.76 & 0.19 & 4 & -9.97 & 0.14 & 4 & -10.43 & 0.15 & 4 & -8.75 & 0.19 & 4 & -7.79 & 0.13 & 4 \\
\hline C289A & -10.21 & 0.24 & 5 & -8.08 & 0.28 & 5 & -8.51 & 0.27 & 5 & -8.13 & 0.52 & & & & \\
\hline W290A & -9.89 & 0.19 & $4 \mathrm{I}$ & ND & & & -7.76 & 0.27 & 4 & -7.22 & 0.55 & 4 & -7.54 & 0.30 & 4 \\
\hline L291A & -10.20 & 0.20 & 4 & -7.42 & 0.20 & 4 & -8.80 & 0.18 & 4 & -7.52 & 0.24 & 4 & -7.03 & 0.26 & 7 \\
\hline S292A & -9.31 & 0.14 & 4 & -8.98 & 0.10 & 5 & -9.45 & 0.09 & 4 & -7.92 & 0.12 & 4 & -7.33 & 0.12 & 4 \\
\hline V293A & -10.01 & 0.12 & 4 & -9.66 & 0.11 & 5 & -9.76 & 0.12 & 4 & -9.03 & 0.13 & 4 & -8.17 & 0.15 & 4 \\
\hline E294A & -10.58 & 0.22 & 4 & -9.55 & 0.17 & 4 & -10.15 & 0.21 & 4 & -8.71 & 0.23 & 4 & -7.54 & 0.28 & 4 \\
\hline T295A & -10.36 & 0.26 & 4 & -8.54 & 0.25 & 4 & -9.36 & 0.24 & 4 & -8.39 & 0.40 & 4 & -7.97 & 0.41 & 8 \\
\hline H296A & -10.66 & 0.23 & 4 & -9.70 & 0.19 & 4 & -10.52 & 0.24 & 4 & -8.65 & 0.26 & 4 & -7.57 & 0.32 & 4 \\
\hline L297A & -10.39 & 0.17 & 7 & -8.52 & 0.16 & 7 & -9.60 & 0.15 & 7 & -8.86 & 0.21 & 7 & -7.45 & 0.19 & 7 \\
\hline L298A & -10.23 & 0.14 & 7 & -8.73 & 0.11 & 7 & -9.95 & 0.13 & 7 & -8.77 & 0.14 & 7 & -7.38 & 0.18 & 7 \\
\hline Y299A & -10.41 & 0.22 & 5 & -8.96 & 0.20 & 5 & -9.57 & 0.22 & 5 & -8.20 & 0.27 & 5 & -7.21 & 0.33 & 8 \\
\hline I300A & -9.91 & 0.22 & 7 & -8.41 & 0.17 & 6 & -8.98 & 0.20 & 6 & -7.98 & 0.27 & 7 & -7.08 & 0.27 & 그 \\
\hline WT (ECL3) & -10.73 & 0.08 & 26 & -10.28 & 0.07 & 29 & -10.22 & 0.07 & 25 & -8.79 & 0.06 & 25 & -7.73 & 0.06 & 27 \\
\hline F356A & -10.24 & 0.19 & 5 & -8.36 & 0.19 & 5 & -8.85 & 0.18 & 5 & -8.61 & 0.15 & 5 & -8.07 & 0.14 & 5 \\
\hline V357A & -10.07 & 0.15 & 5 & -8.88 & 0.14 & 5 & -9.16 & 0.15 & 5 & -8.30 & 0.16 & 5 & -7.32 & 0.23 & 5 \\
\hline V358A & -10.28 & 0.15 & 5 & -9.35 & 0.18 & 4 & -9.92 & 0.16 & 4 & -8.35 & 0.21 & 4 & -7.37 & 0.36 & 4 \\
\hline F359A & -10.26 & 0.12 & 5 & -8.72 & 0.13 & 4 & -9.09 & 0.12 & 4 & -7.81 & 0.15 & 4 & -7.26 & 0.27 & 4 \\
\hline P360A & -10.68 & 0.20 & 4 & -8.74 & 0.18 & 4 & -9.46 & 0.16 & 4 & -8.08 & 0.22 & 4 & -7.02 & 0.59 & 5 \\
\hline W361A & -10.36 & 0.15 & 5 & -9.65 & 0.17 & 5 & -9.41 & 0.16 & 6 & -8.07 & 0.25 & 5 & -7.25 & 0.27 & 5 \\
\hline R362A & -10.61 & 0.23 & 4 & -8.55 & 0.23 & 4 & -8.77 & 0.22 & 4 & -8.39 & 0.23 & 4 & -7.37 & 0.34 & 4 \\
\hline P363A & -10.48 & 0.30 & 4 & -8.65 & 0.28 & 4 & -9.30 & 0.31 & 4 & -7.65 & 0.96 & & & & \\
\hline S364A & -10.41 & 0.25 & 5 & -9.85 & 0.21 & 5 & -9.88 & 0.19 & 5 & -8.48 & 0.18 & 5 & -7.51 & 0.18 & 5 \\
\hline N365A & -10.52 & 0.15 & 5 & -9.70 & 0.13 & 5 & -9.80 & 0.13 & 5 & -8.39 & 0.11 & 5 & -7.40 & 0.12 & 5 \\
\hline K366A & -11.03 & 0.22 & 4 & -10.23 & 0.20 & 4 & -10.90 & 0.18 & 4 & -9.21 & 0.18 & 4 & -7.74 & 0.16 & 4 \\
\hline M367A & -11.32 & 0.33 & 3 & -10.38 & 0.26 & 3 & -11.08 & 0.24 & 3 & -9.11 & 0.27 & 3 & -7.63 & 0.19 & 3 \\
\hline L368A & -10.52 & 0.22 & 5 & -9.52 & 0.19 & 5 & -9.79 & 0.19 & 5 & -7.84 & 0.21 & 5 & -6.94 & 0.29 & 5 \\
\hline G369A & -10.59 & 0.22 & 4 & -10.25 & 0.27 & 4 & -10.26 & 0.22 & 4 & -8.32 & 0.26 & 4 & -7.38 & 0.26 & 4 \\
\hline K370A & -10.67 & 0.22 & 5 & -10.04 & 0.22 & 5 & -10.04 & 0.19 & 5 & -8.88 & 0.16 & 5 & -7.76 & 0.16 & 5 \\
\hline I371A & -10.60 & 0.23 & 4 & -10.11 & 0.20 & 4 & -9.98 & 0.19 & 4 & -8.49 & 0.20 & 4 & -7.39 & 0.24 & 3 \\
\hline Y372A & -10.61 & 0.17 & 5 & -8.41 & 0.18 & 5 & -8.22 & 0.22 & 5 & -8.20 & 0.16 & 5 & -7.22 & 0.30 & 5 \\
\hline D373A & -10.49 & 0.12 & 5 & -8.75 & 0.11 & 5 & -8.46 & 0.15 & 5 & -7.52 & 0.46 & & & & \\
\hline Y374A & -10.82 & 0.27 & 5 & -9.72 & 0.24 & 5 & -9.93 & 0.24 & 5 & -8.66 & 0.20 & 5 & -7.58 & 0.25 & 4 \\
\hline V375A & -11.15 & 0.43 & 3 & -10.70 & 0.38 & 3 & -10.98 & 0.35 & 3 & -9.20 & 0.39 & 3 & -7.79 & 0.26 & 3 \\
\hline M376A & -10.30 & 0.14 & 5 & -8.66 & 0.18 & 4 & -9.29 & 0.19 & 4 & -8.08 & 0.20 & 4 & -7.33 & 0.31 & 4 \\
\hline
\end{tabular}

${ }^{a}$ For each receptor mutant and ligand, concentration-response data for each pathway were fit with the Black and Leff operational model to derive an affinity-independent measure of efficacy and functional affinity $\left(\log K_{\mathrm{A}}\right)$. Mean, S.E.M., and the individual experimental " $n$ " values are reported. Significance of changes in $\log K_{\mathrm{A}}$ of each ligand was determined by comparison of mutant receptors to WT values by a one-way ANOVA and Dunnett's post-test $(p<0.05$ denoted by bold coloured entries. Orange, significant decrease $\leq 10$-fold; red, significant decrease $>10$-fold; Light green, significant increase $\leq 10$-fold; Dark green, significant increase $>10$-fold). ND, data were not able to be reliably determined.

responses, but not those of CT peptides, suggesting that they are important for initiation or propagation of pERK signaling (Figure 5I,J, see red arrows).

The equivalent amino acids in CTR did not impact on pERK functional affinity of these peptides (Figure 7D,E versus Figure 7I,J), consistent with RAMP3 allosterically altering interaction of rAmy and hCGRP with this segment of the receptor, potentially through effects on engagement of the receptor with the midregion of the agonist peptide $\alpha$-helix.

In general, the effect of ECL2 and ECL3 mutation was similar for $\mathrm{AMY}_{3} \mathrm{R}$ and $\mathrm{CTR}$ for cAMP functional affinity (Figure 6), for most peptides, although RAMP3 appeared to impart increased sensitivity to mutation for hCT and pCT. The exception to this was hCGRP in which a greater effect of mutation was seen for CTR relative to $\mathrm{AMY}_{3} \mathrm{R}$ (Figure $6 \mathrm{E}$ versus Figure $6 \mathrm{~J}$ ), and this might reflect increased strength of interaction of this peptide at the $\mathrm{AMY}_{3} \mathrm{R}$ such that individual mutation of amino acids had lesser effect.

Intriguingly, while overall there was relatively limited impact of ECL2 or ECL3 mutation on pERK functional affinity for either $\mathrm{AMY}_{3} \mathrm{R}$ or CTR, there was a greater effect of mutation on CTR, particularly for CT peptides and within ECL3 (Figure
7A-C versus $7 \mathrm{~F}-\mathrm{H}$ ). This greater effect on CTR mutation occurred for select amino acids deep in the peptide binding pocket, with additional effects on $\mathrm{pCT}$ for residues that extended, in 3D space, from the peptide proximal residues.

Peptide Efficacy. The operationally derived efficacy parameter, $\tau$, is a measure of pathway-specific coupling efficiency that relates the number of receptors occupied to response. ${ }^{19}$ Peptide efficacy for cAMP accumulation was largely unaffected by mutation to ECL2 residues (Figure $8 \mathrm{~A}-\mathrm{E}$, Table 4), albeit that the relatively high variance may have limited those effects that achieved statistical significance.

Overall, ECL2 mutation tended to lead to increased measures of peptide efficacy for CT peptides (Figure 8A$\mathrm{C})$, with effects achieving significance for S292A mutation (sCT, pCT), L298A (sCT) and I300A (hCT). Increased efficacy of rAmy was also observed with the S292A mutant (Figure 8D). In contrast, both increased and decreased efficacy was observed following mutation of amino acids in ECL3, in a peptide-dependent manner (Figure 8F-J). Greater numbers of mutations had significant effects within ECL3; however, this was partially attributable to more robust expression of ECL3 
Table 3. Effect of Single Alanine Mutation in $\mathrm{AMY}_{3} \mathrm{R}$ ECL2 or ECL3 on pERK Functional Affinity $\left(\log K_{\mathrm{A}}\right)$ of Peptides ${ }^{a}$

\begin{tabular}{|c|c|c|c|c|c|c|c|c|c|c|c|c|c|c|c|}
\hline & sCT & & & hCT & & & CT & & & ramy & & & hCGRP & & \\
\hline & Mean & S.E.M. & $\mathbf{N}$ & Mean & S.E.M. & $\mathbf{N}$ & Mean & S.E.M. & $\mathrm{N}$ & Mean & S.E.M. & $\mathbf{N}$ & Mean & S.E.M. & $\mathrm{N}$ \\
\hline WT (ECL2) & -8.13 & 0.17 & 27 & -7.81 & 0.15 & 33 & -8.36 & 0.16 & 31 & -7.83 & 0.10 & 33 & -7.54 & 0.16 & 25 \\
\hline $1279 A$ & -7.91 & 0.31 & 5 & -7.41 & 0.27 & 7 & -8.35 & 0.27 & 6 & -7.74 & 0.15 & 7 & -7.73 & 0.22 & 5 \\
\hline T280A & -8.69 & 0.31 & 5 & -8.26 & 0.42 & 8 & -8.53 & 0.31 & 6 & -7.46 & 0.31 & 7 & -7.28 & 0.38 & 7 \\
\hline R281A & -9.45 & 0.55 & 6 & ND & & & -7.52 & 0.55 & 6 & -8.02 & 0.38 & 8 & -7.39 & 1.40 & 6 \\
\hline V283A & -8.61 & 0.28 & 5 & -7.77 & 0.25 & 7 & -8.39 & 0.26 & 7 & -7.79 & 0.18 & 8 & -6.91 & 0.26 & 6 \\
\hline Y284A & -8.59 & 0.54 & 7 & -8.25 & 0.57 & 6 & -7.77 & 0.46 & 5 & -6.69 & 0.35 & 5 & -6.90 & 0.70 & 5 \\
\hline F285A & -8.94 & 0.57 & 6 & -8.02 & 0.50 & 7 & -9.19 & 0.61 & 5 & -7.49 & 0.43 & 6 & -7.02 & 0.90 & 5 \\
\hline N286A & -9.18 & 0.77 & 6 & -7.12 & 0.77 & 6 & -8.36 & 1.02 & 5 & -7.85 & 0.66 & 6 & -6.54 & 1.24 & 5 \\
\hline D287A & -8.54 & 0.67 & 6 & ND & & & ID & & & -7.59 & 0.70 & & ND & & \\
\hline N288A & -8.73 & 0.29 & 6 & -7.48 & 0.29 & 6 & -8.47 & 0.39 & 5 & -8.03 & 1.14 & 3 & -7.47 & 0.26 & 6 \\
\hline C289A & -9.09 & 0.84 & 6 & ND & & & 7.35 & 1.59 & 5 & ND & & & -6.62 & 0.63 & 6 \\
\hline W290A & -8.51 & 0.38 & 6 & -6.63 & 1.22 & 7 & -7.04 & 0.71 & 5 & -7.49 & 0.49 & 6 & -7.49 & 1.62 & 5 \\
\hline L291A & -8.90 & 0.69 & 5 & ND & & & -7.39 & 0.63 & 6 & -7.92 & 0.78 & & ND & & \\
\hline S292A & -9.12 & 0.45 & 6 & -8.02 & 0.46 & 7 & -8.13 & 0.46 & 5 & -7.65 & 0.46 & 6 & -7.72 & 0.83 & 6 \\
\hline V293A & -8.46 & 0.30 & 6 & -7.83 & 0.30 & 7 & -7.86 & 0.32 & 5 & -7.72 & 0.27 & 6 & -7.65 & 0.31 & 6 \\
\hline E294A & -8.32 & 0.31 & 4 & -7.90 & 0.25 & 7 & -8.67 & 0.25 & 7 & -7.92 & 0.17 & 9 & -7.09 & 0.26 & 6 \\
\hline T295A & -8.81 & 0.35 & 6 & -7.07 & 0.93 & 8 & -8.19 & 0.95 & 4 & -7.84 & 0.79 & 7 & -6.66 & 1.16 & 7 \\
\hline H296A & -8.16 & 0.27 & 5 & -7.71 & 0.25 & 7 & -8.60 & 0.24 & 7 & -7.60 & 0.17 & 8 & -7.51 & 0.29 & 6 \\
\hline L297A & -9.15 & 0.39 & 5 & -7.19 & 0.37 & 6 & -8.74 & 0.39 & 5 & -7.97 & 0.33 & 4 & -6.83 & 0.46 & 4 \\
\hline L298A & -8.33 & 0.71 & 3 & -7.28 & 0.65 & 3 & -8.38 & 0.77 & 3 & -7.02 & 0.83 & & ND & & \\
\hline Y299A & -9.15 & 0.48 & 6 & -7.51 & 1.01 & 5 & -7.95 & 0.98 & 5 & -7.29 & 0.67 & & ND & & \\
\hline $1300 \mathrm{~A}$ & -8.94 & 0.55 & 5 & -8.04 & 0.63 & 6 & -8.46 & 0.52 & 6 & -8.35 & 0.44 & 6 & -7.16 & 0.80 & 4 \\
\hline WT (ECL3) & -7.13 & 0.23 & 28 & -7.19 & 0.20 & 24 & -7.43 & 0.23 & 21 & -6.79 & 0.24 & 23 & -7.03 & 0.19 & 24 \\
\hline F356A & -8.20 & 0.48 & 6 & -6.85 & 0.80 & 6 & -7.11 & 0.52 & 6 & -7.37 & 0.43 & 6 & -7.12 & 0.31 & 6 \\
\hline V357A & -8.45 & 0.48 & 6 & -7.09 & 0.53 & 6 & -8.26 & 0.43 & 6 & -7.98 & 0.43 & 6 & -6.96 & 0.46 & 6 \\
\hline V358A & -8.04 & 0.43 & 6 & -7.67 & 0.54 & 4 & -8.23 & 0.84 & 4 & -7.25 & 0.80 & 4 & -7.37 & 1.21 & 4 \\
\hline F359A & -8.00 & 0.36 & 6 & -7.58 & 0.50 & 4 & -8.33 & 0.63 & 4 & -7.29 & 0.61 & 4 & -7.25 & 1.27 & 4 \\
\hline P360A & -7.34 & 0.41 & 6 & -6.92 & 0.62 & 5 & -7.31 & 0.53 & 5 & -6.96 & 0.48 & & ND & & 5 \\
\hline W361A & -8.22 & 0.41 & 4 & -7.13 & 0.48 & 3 & -7.34 & 0.49 & 3 & -6.66 & 0.57 & 3 & -7.84 & 0.94 & 3 \\
\hline R362A & 8.20 & 1.43 & 3 & 6.40 & 1.48 & 3 & -7.49 & 1.56 & 31 & ND & & & ND & & \\
\hline P363A & -7.68 & 0.58 & 5 & -6.72 & 0.75 & 5 & -7.72 & 0.71 & 5 & ND & & & ND & & \\
\hline S364A & -6.84 & 0.44 & 6 & -6.95 & 0.41 & 5 & -8.02 & 0.46 & 3 & -7.35 & 0.37 & 4 & -7.00 & 0.30 & 5 \\
\hline N365A & -7.26 & 0.38 & 6 & -6.72 & 0.42 & 5 & -7.99 & 0.46 & 3 & -7.69 & 0.34 & 4 & -6.38 & 0.40 & 5 \\
\hline K366A & -8.29 & 0.69 & 3 & -7.95 & 0.57 & 3 & -8.51 & 0.82 & 3 & -7.99 & 0.90 & 3 & -7.15 & 0.68 & 3 \\
\hline M367A & -6.90 & 0.83 & 3 & -7.13 & 0.66 & 3 & -7.48 & 0.67 & 3 & -7.16 & 0.89 & 3 & -7.70 & 0.80 & 3 \\
\hline L368A & -7.84 & 0.35 & 6 & -8.25 & 0.42 & 4 & -8.87 & 0.34 & 5 & -6.97 & 0.41 & 5 & -6.76 & 0.53 & 5 \\
\hline G369A & -8.00 & 0.76 & 3 & -7.92 & 0.71 & 3 & -8.07 & 0.83 & 3 & -7.01 & 1.11 & 3 & -7.14 & 1.11 & 3 \\
\hline K370A & -7.59 & 0.41 & 6 & -6.38 & 0.49 & 5 & -7.61 & 0.43 & 4 & -6.05 & 1.07 & 3 & -7.32 & 0.58 & 3 \\
\hline I371A & -8.22 & 1.03 & 3 & ND & & & -7.52 & 1.17 & 3 & -8.02 & 1.71 & & ND & & \\
\hline Y372A & -6.88 & 0.44 & 6 & -6.21 & 0.79 & 6 & -7.24 & 1.04 & 5 & -7.55 & 0.92 & 5 & -7.15 & 1.01 & 5 \\
\hline D373A & -7.30 & 0.48 & 6 & -6.47 & 0.56 & 6 & -6.22 & 1.05 & 5 & ND & & & -6.43 & 1.02 & 5 \\
\hline Y374A & -7.31 & 0.38 & 6 & -6.99 & 0.37 & 5 & -6.85 & 0.46 & 4 & -6.29 & 0.49 & 5 & -7.05 & 0.38 & 5 \\
\hline V375A & -7.32 & 0.55 & 6 & -7.93 & 0.98 & 5 & -7.99 & 1.01 & 4 & -6.56 & 1.52 & & ND & & \\
\hline M376A & -7.87 & 0.72 & 6 & -6.78 & 1.42 & 4 & -7.60 & 1.40 & 4 & -6.56 & 1.89 & & ND & & \\
\hline
\end{tabular}

${ }^{a}$ For each receptor mutant and ligand, concentration-response data for each pathway were fit with the Black and Leff operational model to derive an affinity-independent measure of efficacy and functional affinity $\left(\log K_{\mathrm{A}}\right)$. Mean, S.E.M. and the individual experimental " $n$ " values are reported. $\mathrm{ND}$, data were not able to be reliably determined. Where quantitative data could be derived, no significant differences from WT values were observed, as assessed by a one-way ANOVA and Dunnett's post-test (significance set at $p<0.05$ ).

mutants (Figure 1, Table 1) and greater precision in the calculation of $\log \tau$ (Table 4).

The pattern of effect was similar for CT peptides, with increased efficacy for each peptide observed with the F356A, V358A, N365A, and D373A mutants and loss of efficacy for the V375A mutant (Figure $8 \mathrm{~F}-\mathrm{H}$ ). Nonetheless, peptide specific effects were also observed with increased efficacy at the V358A (sCT), F359A (sCT, pCT), W361A (sCT), and M376A (sCT) mutants. Selective attenuation of efficacy was seen at the G369A and K370A (hCT) and Y372A (pCT) mutants (Figure $8 \mathrm{~F}-\mathrm{H}$ ). While there were parallels in the effect of the F356A and N365A mutation for rAmy and hCGRP, the pattern of effect was generally distinct (Figure $8 \mathrm{I}, \mathrm{J})$, and more similar for these two peptides than between them and the CT peptides (Figure $8 \mathrm{~F}-\mathrm{J}$ ). Of all the ECL3 mutants, only the F356A and N365A mutants had equivalent effect (increased efficacy) on rAmy, hCGRP, and CT peptides, while the effects of increased efficacy (V357A) and decreased efficacy (V375A) were also observed for rAmy but not hCGRP. Similar effects, distinct from those for CT peptides, were observed for both rAmy and hCGRP for P360A, W361A, P363A, and D373A (decreased efficacy or ND), with the nature of effect of the D373A mutant opposite to that seen for all CT peptides (Figure 8F-J). Peptide-specific loss of efficacy was seen for V358A, F359A, R362A, Y372A (hCGRP), M367A, and G369A (rAmy) (Figure 8I,J).

Remarkably, there was a dramatic loss of peptide efficacy for pERK for most individual mutants within both ECL2 and ECL3 (Figure 9, Table 5), although there was a lesser effect of ECL2 mutation on hCGRP efficacy (Figure 9E). Within ECL2, only I279A did not have any negative effect on CT or Amy peptide efficacy, albeit that the loss of efficacy did not achieve significance for V283A (hCT, pCT, rAmy), Y284A (rAmy), N288A (hCT), V293A (pCT), E294A, H296A (sCT, hCT, pCT, rAmy), L297A (hCT, pCT, rAmy), and L298A (hCT) (Figure 9A-D, Table 5). As noted above, for hCGRP, no robust response was observed for D287A, L291A, L298A, and Y299A (Tables 3, 5). Of the other ECL2 mutants, only the S292A mutant produced a significant loss of hCGRP efficacy (Figure 9E). Like ECL2, alanine mutation of ECL3 broadly led to loss of peptide efficacy (Figure 9F-J). For this loop, the pattern of effect was also mirrored for hCGRP (Figure 9J). Of the ECL3 residues, only S364A, N365A, and Y284A did not significantly reduce efficacy of any of the peptides (Table 5). For W361A and L368A, while loss of efficacy occurred for all peptides, this was not statistically significant for some of the 
Table 4. Effect of Single Alanine Mutation in AMY $\mathrm{A}_{3}$ ECL2 or ECL3 on cAMP Signaling Efficacy (log $\left.\tau_{\mathrm{c}}\right)$ of Peptides ${ }^{a}$

\begin{tabular}{|c|c|c|c|c|c|c|c|c|c|c|c|c|c|c|c|}
\hline & SCT & & & hCT & & & CT & & & my & & & hCGRP & & \\
\hline & Mean & S.E.M. & $\mathbf{N}$ & Mean & S.E.M. & $\mathbf{N}$ & Mean & S.E.M. & $\mathbf{N}$ & Mean & S.E.M. & $\mathbf{N}$ & Mean & S.E.M. & $\mathbf{N}$ \\
\hline WT (ECL2) & -0.18 & 0.02 & 26 & -0.19 & 0.02 & 23 & -0.18 & 0.02 & 26 & -0.18 & 0.02 & 26 & -0.20 & 0.02 & 34 \\
\hline 1279A & -0.37 & 0.06 & 4 & -0.40 & 0.06 & 4 & -0.38 & 0.06 & 4 & -0.36 & 0.06 & 4 & -0.43 & 0.07 & 4 \\
\hline T280A & -0.19 & 0.09 & 4 & -0.12 & 0.09 & 11 & -0.22 & 0.09 & 4 & -0.24 & 0.10 & 4 & -0.29 & 0.10 & 4 \\
\hline R281A & 0.39 & 0.31 & 4 & ND & & 4 & 0.32 & 0.31 & 4 & 0.15 & 0.32 & 4 & -0.22 & 0.33 & 7 \\
\hline V283A & -0.30 & 0.06 & 4 & -0.33 & 0.05 & 4 & -0.37 & 0.05 & 4 & -0.39 & 0.06 & 4 & -0.51 & 0.08 & 4 \\
\hline Y284A & -0.20 & 0.09 & 4 & -0.14 & 0.09 & 4 & -0.15 & 0.09 & 4 & -0.22 & 0.10 & 4 & -0.24 & 0.10 & 4 \\
\hline F285A & 0.08 & 0.13 & 4 & -0.11 & 0.13 & 5 & -0.04 & 0.13 & 4 & -0.18 & 0.14 & 4 & -0.15 & 0.14 & 4 \\
\hline N286A & 0.20 & 0.10 & 4 & 0.04 & 0.10 & 5 & 0.09 & 0.10 & 4 & 0.00 & 0.11 & 4 & -0.12 & 0.14 & 4 \\
\hline D287A & 0.46 & 0.20 & 4 & 0.19 & 0.22 & 5 & 0.12 & 0.22 & 4 & -0.11 & 0.22 & 7 & -0.29 & 0.23 & 6 \\
\hline N288A & -0.26 & 0.05 & 4 & -0.16 & 0.04 & 4 & -0.16 & 0.04 & 4 & -0.31 & 0.05 & 4 & -0.08 & 0.05 & 4 \\
\hline C289A & 0.27 & 0.26 & 5 & 0.08 & 0.26 & 5 & 0.15 & 0.26 & 5 & -0.34 & 0.27 & & ND & & \\
\hline W290A & 0.49 & 0.27 & 4 & ND & & 8 & 0.23 & 0.27 & 4 & -0.04 & 0.30 & 4 & 0.15 & 0.27 & 4 \\
\hline L291A & 0.13 & 0.08 & 4 & 0.12 & 0.09 & 4 & 0.08 & 0.08 & 4 & 0.03 & 0.10 & 4 & -0.34 & 0.10 & 7 \\
\hline S292A & 1.10 & 0.10 & 4 & 0.42 & 0.05 & 5 & 0.61 & 0.05 & 4 & 0.96 & 0.09 & 4 & 0.27 & 0.05 & 4 \\
\hline V293A & 0.24 & 0.05 & 4 & -0.14 & 0.04 & 5 & -0.05 & 0.04 & 4 & -0.03 & 0.05 & 4 & -0.19 & 0.05 & 4 \\
\hline E294A & -0.27 & 0.05 & 4 & -0.24 & 0.05 & 4 & -0.32 & 0.05 & 4 & -0.34 & 0.06 & 4 & -0.46 & 0.08 & 4 \\
\hline T295A & 0.31 & 0.26 & 4 & 0.25 & 0.26 & 4 & 0.29 & 0.26 & 4 & 0.06 & 0.27 & 4 & -0.26 & 0.27 & 8 \\
\hline H296A & -0.35 & 0.06 & 4 & -0.36 & 0.05 & 4 & -0.43 & 0.05 & 4 & -0.44 & 0.07 & 4 & -0.58 & 0.09 & 4 \\
\hline L297A & 0.24 & 0.21 & 7 & 0.19 & 0.21 & 7 & 0.22 & 0.21 & 7 & 0.04 & 0.21 & 7 & 0.12 & 0.21 & 7 \\
\hline L298A & 0.39 & 0.15 & 7 & 0.39 & 0.15 & 7 & 0.28 & 0.15 & 7 & 0.29 & 0.15 & 7 & 0.17 & 0.15 & 7 \\
\hline Y299A & 0.12 & 0.27 & 5 & 0.04 & 0.27 & 5 & 0.04 & 0.27 & 5 & -0.03 & 0.28 & 5 & -0.36 & 0.28 & 8 \\
\hline I300A & 0.35 & 0.43 & 7 & 0.48 & 0.43 & 6 & 0.37 & 0.43 & 6 & 0.22 & 0.43 & 7 & 0.24 & 0.43 & 7 \\
\hline WT (ECL3) & -0.19 & 0.02 & 26 & -0.18 & 0.02 & 29 & -0.19 & 0.02 & 25 & -0.19 & 0.02 & 25 & -0.20 & 0.02 & 27 \\
\hline F356A & 0.25 & 0.07 & 5 & 0.19 & 0.07 & 5 & 0.12 & 0.07 & 5 & 0.19 & 0.06 & 5 & 0.21 & 0.07 & \\
\hline V357A & 0.32 & 0.10 & 5 & 0.28 & 0.10 & 5 & 0.19 & 0.10 & 5 & 0.07 & 0.10 & 5 & -0.10 & 0.11 & 5 \\
\hline V358A & 0.09 & 0.04 & 5 & -0.09 & 0.05 & 4 & -0.07 & 0.04 & 4 & -0.31 & 0.05 & 4 & -0.58 & 0.09 & 4 \\
\hline F359A & 0.06 & 0.05 & 5 & -0.04 & 0.05 & 4 & 0.11 & 0.05 & 4. & -0.30 & 0.05 & 4 & -0.66 & 0.08 & 4 \\
\hline P360A & -0.31 & 0.05 & 4 & -0.31 & 0.05 & 4 & -0.23 & 0.05 & 4 & -0.54 & 0.06 & 4 & -1.19 & 0.15 & 5 \\
\hline W361A & 0.01 & 0.06 & 5 & -0.18 & 0.06 & 5 & -0.20 & 0.06 & 6 & -0.50 & 0.08 & 5 & -0.49 & 0.09 & 5 \\
\hline R362A & -0.22 & 0.06 & 4 & -0.24 & 0.07 & 4 & -0.29 & 0.06 & 4 & -0.36 & 0.06 & 4 & -0.53 & 0.09 & 4 \\
\hline P363A & -0.24 & 0.08 & 4 & -0.26 & 0.09 & 4 & -0.34 & 0.08 & 4 & -0.94 & 0.21 & $4 \mathrm{~N}$ & ND & & \\
\hline S364A & -0.30 & 0.06 & 5 & -0.29 & 0.06 & 5 & -0.27 & 0.06 & 5 & -0.25 & 0.06 & 5 & -0.26 & 0.07 & 5 \\
\hline N365A & 0.12 & 0.07 & 5 & 0.11 & 0.07 & 5 & 0.06 & 0.06 & 5 & 0.19 & 0.07 & 5 & 0.12 & 0.07 & 5 \\
\hline K366A & -0.22 & 0.04 & 4 & -0.21 & 0.04 & 4 & -0.25 & 0.04 & 4 & -0.28 & 0.04 & 4 & -0.20 & 0.05 & 4 \\
\hline M367A & -0.43 & 0.06 & 3 & -0.37 & 0.06 & 3 & -0.38 & 0.05 & 3 & -0.51 & 0.06 & 3 & -0.28 & 0.07 & 3 \\
\hline L368A & -0.14 & 0.08 & 5 & -0.13 & 0.08 & 5 & -0.21 & 0.07 & 5 & -0.28 & 0.08 & 5 & -0.39 & 0.11 & 5 \\
\hline G369A & -0.23 & 0.05 & 4 & -0.42 & 0.06 & 4 & -0.32 & 0.05 & 4 & -0.48 & 0.06 & 4 & -0.43 & 0.08 & 4 \\
\hline K370A & -0.36 & 0.05 & 5 & -0.42 & 0.05 & 5 & -0.38 & 0.05 & 5 & -0.35 & 0.05 & 5 & -0.32 & 0.05 & 5 \\
\hline I371A & -0.24 & 0.07 & 4 & -0.19 & 0.07 & 4 & -0.23 & 0.07 & 4 & -0.29 & 0.07 & 4 & -0.27 & 0.09 & 3 \\
\hline Y372A & -0.26 & 0.05 & 5 & -0.27 & 0.06 & 5 & -0.46 & 0.06 & 5 & -0.36 & 0.06 & 5 & -0.69 & 0.09 & 5 \\
\hline D373A & 0.43 & 0.06 & 5 & 0.50 & 0.06 & 5 & 0.12 & 0.06 & 5 & -0.58 & 0.12 & $5 \mathrm{~N}$ & ND & & \\
\hline Y374A & -0.25 & 0.08 & 5 & -0.24 & 0.08 & 5 & -0.27 & 0.08 & 5 & -0.22 & 0.08 & 5 & -0.27 & 0.09 & 4 \\
\hline V375A & -0.54 & 0.08 & 3 & -0.55 & 0.08 & 3 & -0.55 & 0.07 & 3 & -0.66 & 0.09 & 3 & -0.42 & 0.08 & 3 \\
\hline M376A & 0.14 & 0.07 & 5 & -0.07 & 0.07 & 4 & -0.11 & 0.07 & 4 & -0.24 & 0.07 & 4 & -0.46 & 0.10 & 4 \\
\hline
\end{tabular}

${ }^{a}$ For each receptor mutant and ligand, concentration-response data for each pathway were fit with the Black and Leff operational model to derive an affinity-independent measure of efficacy $(\log \tau)$ and functional affinity. These data were corrected for changes in cell surface expression from FACS to yield $\log \tau_{c}$. Mean, S.E.M., and the individual experimental " $n$ " values are reported. Significance of changes in log $\tau_{\mathrm{c}}$ of each ligand was determined by comparison of mutant receptors to WT values by a one-way ANOVA and Dunnett's post-test $(p<0.05$ denoted by bold coloured entries. Orange, significant decrease $\leq 10$-fold; red, significant decrease $>10$-fold; light green, significant increase $\leq 10$-fold; dark green, significant increase $>10$-fold). ND, data were not able to be reliably determined.

peptides. Of the other mutants only K370A (hCT), F357A, and D373A (hCGRP) did not have significant effects on pERK peptide efficacy (Figure 9F-J).

Mapping the effects of ECL2 and ECL3 mutation onto the 3D $\mathrm{AMY}_{3} \mathrm{R}$ model revealed major differences in the effect of alanine mutation on the two signaling pathways (Figure 10). Mutations through the core of ECL2 dramatically reduced CT peptide and rAmy efficacy for pERK but had very limited impact on the efficacy in cAMP assays (Figure 10).

Within ECL2, the most notable effect on cAMP efficacy was increased efficacy with the S292A mutation. This contrasts to the decreased functional affinity of the CT peptides for this pathway. S292 is capable of forming polar interactions and, in the CTR, contributes to packing of ECL2 in the active state. ${ }^{16}$ Nonetheless, in CTR the S292A mutation does not alter either affinity or efficacy of peptides for this pathway. ${ }^{17}$ This suggests that RAMP3 allosterically alters CTR ECL2 conformation, potentially allowing this residue to interact with rAmy and CT peptides when coupled to Gs.

Within ECL3, the mutation of residues at the proximal end of TM6 that are located deep in the peptide binding pocket led to enhanced cAMP efficacy for all peptides (Figure 10A-E). Interestingly, N365, whose alanine mutation also enhanced cAMP efficacy for all peptides, is located at the external face of the receptor (Figure 10A-E), and thus may make polar interactions with lipid head groups that constrain conformational propagation for Gs engagement in the context of the $\mathrm{AMY}_{3} \mathrm{R}$. This amino acid was one of very few that did not adversely affect pERK efficacy (Figure 10A-E versus Figure $10 \mathrm{~F}-\mathrm{J})$, suggesting that such a constraint does not affect nonGs pathways. We have previously shown that pERK is independent of cAMP-dependent PKA activity, and PTXsensitive $\mathrm{Gi} / \mathrm{o}$ proteins for the $\mathrm{AMY}_{3} \mathrm{R}^{7}$ indicating that, like CTR, the effect of mutations on the two measured pathways reveal distinct conformational propagation pathways. Comparison of the effect of mutation on $\mathrm{AMY}_{3} \mathrm{R}$ and CTR pointed to peptide-specific influence on cAMP efficacy (Figure 11).

Intriguingly, while the pattern of effect was similar, alanine mutation in ECL3 had greater impact on sCT efficacy at $\mathrm{AMY}_{3} \mathrm{R}$ compared to CTR, with mutation of the deeper, peptide-proximal residues within ECL3 enhancing cAMP efficacy (Figure 11A versus Figure 11F), implying a role for 
Table 5. Effect of Single Alanine Mutation in $\mathrm{AMY}_{3} \mathrm{R}$ ECL2 or ECL3 on pERK Signaling Efficacy $\left(\log \tau_{\mathrm{c}}\right)$ of Peptides ${ }^{a}$

\begin{tabular}{|c|c|c|c|c|c|c|c|c|c|c|c|c|c|c|c|}
\hline & sCT & & & hCT & & & pCT & & & ramy & & & hCGRP & & \\
\hline & Mean & S.E.M. & $\mathbf{N}$ & Mean & S.E.M. & $\mathbf{N}$ & Mean & S.E.M. & $\mathbf{N}$ & Mean & S.E.M. & $\mathbf{N}$ & Mean & S.E.M. & $\mathbf{N}$ \\
\hline WT (ECL2) & 0.86 & 0.11 & 27 & 0.88 & 0.10 & 33 & 0.84 & 0.10 & 31 & 0.04 & 0.04 & 33 & -0.50 & 0.07 & 25 \\
\hline 1279A & 1.05 & 0.24 & 5 & 1.09 & 0.21 & 7 & 0.94 & 0.18 & 6 & 0.31 & 0.09 & 7 & -0.43 & 0.10 & 5 \\
\hline T280A & -0.36 & 0.17 & 5 & -1.29 & 0.20 & 8 & -0.30 & 0.16 & 6 & -1.13 & 0.16 & 7 & -1.03 & 0.20 & 7 \\
\hline R281A & -0.93 & 0.37 & 6 & ND & & & -0.53 & 0.40 & 6 & -0.91 & 0.35 & 8 & -1.45 & 0.60 & 6 \\
\hline V283A & -0.15 & 0.14 & 5 & 0.11 & 0.14 & 7 & 0.09 & 0.13 & 7 & -0.48 & 0.09 & 8 & -0.42 & 0.12 & 6 \\
\hline Y284A & -1.52 & 0.26 & 7 & -1.48 & 0.25 & 6 & -0.75 & 0.23 & 5 & -0.72 & 0.20 & 5 & -1.34 & 0.33 & 5 \\
\hline F285A & -1.52 & 0.27 & 6 & -1.37 & 0.25 & 7 & -1.36 & 0.26 & 5 & -1.40 & 0.22 & 6 & -1.57 & 0.41 & 5 \\
\hline N286A & -1.56 & 0.31 & 6 & -1.28 & 0.38 & 6 & -1.63 & 0.40 & 5 & -1.57 & 0.27 & 6 & -1.27 & 0.58 & 5 \\
\hline D287A & -1.10 & 0.35 & 6 & ND & & & ND & & & -1.47 & 0.34 & & ND & & \\
\hline N288A & -0.52 & 0.14 & 6 & -0.04 & 0.16 & 6 & -0.71 & 0.17 & 5 & -2.33 & 0.39 & 3 & -0.69 & 0.12 & 6 \\
\hline C289A & -1.51 & 0.41 & 6 & ND & & & -1.87 & 0.72 & $5 \mathrm{I}$ & ND & & & -0.68 & 0.40 & 6 \\
\hline W290A & -0.26 & 0.32 & 6 & -1.63 & 0.69 & 7 & -0.63 & 0.44 & 5 & -0.99 & 0.34 & 6 & -1.55 & 0.63 & 5 \\
\hline L291A & -1.45 & 0.29 & 5 & ND & & & -1.08 & 0.30 & 6 & -1.81 & 0.30 & & ND & & \\
\hline S292A & -1.24 & 0.19 & 6 & -1.29 & 0.20 & 7 & -0.85 & 0.20 & 5 & -1.56 & 0.20 & 6 & -1.74 & 0.34 & 6 \\
\hline V293A & -0.55 & 0.15 & 6 & -0.55 & 0.14 & 7 & -0.02 & 0.16 & 5 & -1.03 & 0.12 & 6 & -1.00 & 0.16 & 6 \\
\hline E294A & 0.09 & 0.17 & 4 & 0.19 & 0.13 & 7 & 0.15 & 0.12 & 7 & -0.49 & 0.08 & 9 & -0.47 & 0.12 & 6 \\
\hline T295A & -0.18 & 0.30 & 6 & -1.54 & 0.51 & 8 & -1.17 & 0.45 & 4 & -1.63 & 0.39 & 7 & -1.23 & 0.59 & 7 \\
\hline H296A & 0.53 & 0.17 & 5 & 0.30 & 0.14 & 7 & 0.47 & 0.13 & 7 & -0.38 & 0.08 & 8 & -0.81 & 0.14 & 6 \\
\hline L297A & -0.43 & 0.26 & 5 & 0.01 & 0.28 & 6 & -0.17 & 0.26 & 5 & -0.48 & 0.25 & 4 & -0.42 & 0.30 & 4 \\
\hline L298A & -0.82 & 0.35 & 3 & -0.52 & 0.35 & 3 & -0.86 & 0.33 & 3 & -1.23 & 0.39 & & ND & & \\
\hline Y299A & -0.98 & 0.34 & 6 & -1.72 & 0.51 & 5 & -1.57 & 0.48 & 5 & -1.40 & 0.39 & & ND & & \\
\hline $1300 \mathrm{~A}$ & -0.68 & 0.48 & 5 & -0.92 & 0.50 & 6 & -0.53 & 0.48 & 6 & -0.86 & 0.46 & 6 & -0.72 & 0.54 & 4 \\
\hline WT (ECL3) & 1.21 & 0.17 & 28 & 1.16 & 0.15 & 24 & 1.07 & 0.16 & 21 & 1.13 & 0.18 & 23 & 0.68 & 0.12 & 24 \\
\hline F356A & -0.75 & 0.24 & 6 & -1.66 & 0.45 & 6 & -0.79 & 0.29 & 6 & -0.55 & 0.22 & 6 & 0.19 & 0.16 & 6 \\
\hline V357A & -0.95 & 0.23 & 6 & -1.06 & 0.31 & 6 & -0.84 & 0.22 & 6 & -0.82 & 0.22 & 6 & -0.51 & 0.23 & 6 \\
\hline V358A & -0.77 & 0.22 & 6 & -1.22 & 0.27 & 4 & -2.09 & 0.38 & 4 & -1.62 & 0.39 & 4 & -1.79 & 0.46 & 4 \\
\hline F359A & -0.34 & 0.20 & 6 & -1.26 & 0.26 & 4 & -1.79 & 0.29 & 4 & -1.42 & 0.31 & 4 & -2.05 & 0.50 & 4 \\
\hline P360A & -0.42 & 0.24 & 6 & -1.56 & 0.35 & 5 & -1.29 & 0.28 & 5 & -1.09 & 0.26 & & ND & & \\
\hline W361A & 0.09 & 0.23 & 4 & -0.09 & 0.30 & 3 & -0.14 & 0.29 & 3 & -0.24 & 0.36 & 3 & -1.48 & 0.35 & 3 \\
\hline R362A & -2.59 & 0.61 & 3 & -2.09 & 0.91 & 3 & -2.71 & 0.73 & $3 \mathrm{I}$ & ND & & & ND & & \\
\hline P363A & -1.11 & 0.30 & 5 & -1.49 & 0.44 & 5 & -1.73 & 0.35 & $5 \mathrm{I}$ & ND & & & ND & & \\
\hline S364A & 0.38 & 0.30 & 6 & 1.62 & 0.34 & 5 & -0.27 & 0.24 & 3 & 0.22 & 0.22 & 4 & 0.39 & 0.18 & 5 \\
\hline N365A & 0.51 & 0.25 & 6 & 1.20 & 0.33 & 5 & 0.03 & 0.26 & 3 & 0.45 & 0.20 & 4 & 1.04 & 0.31 & 5 \\
\hline K366A & -1.26 & 0.32 & 3 & -1.15 & 0.28 & 3 & -1.86 & 0.35 & 3 & -1.80 & 0.38 & 3 & -0.96 & 0.30 & 3 \\
\hline M367A & -1.12 & 0.49 & 3 & -1.17 & 0.37 & 3 & -1.26 & 0.35 & 3 & -1.61 & 0.44 & 3 & -1.37 & 0.31 & 3 \\
\hline L368A & 0.30 & 0.21 & 6 & -0.60 & 0.21 & 4 & -0.23 & 0.17 & 5 & -0.18 & 0.24 & 5 & -0.65 & 0.26 & 5 \\
\hline G369A & -1.39 & 0.36 & 3 & -1.62 & 0.34 & 3 & -1.81 & 0.38 & 3 & -1.85 & 0.55 & 3 & -1.53 & 0.46 & 3 \\
\hline K370A & -0.55 & 0.23 & 6 & 0.59 & 0.37 & 5 & -0.43 & 0.23 & 4 & -0.65 & 0.75 & 3 & -0.87 & 0.25 & 3 \\
\hline I371A & -2.03 & 0.46 & 3 & ND & & & -2.27 & 0.56 & 3 & -2.69 & 0.67 & & ND & & \\
\hline Y372A & -0.03 & 0.29 & 6 & -1.33 & 0.54 & 6 & -2.53 & 0.53 & 5 & -2.26 & 0.42 & 5 & -0.55 & 0.18 & 5 \\
\hline D373A & -0.58 & 0.27 & 6 & -0.65 & 0.37 & 6 & -1.30 & 0.70 & $5 \mathrm{I}$ & ND & & & 0.25 & 0.05 & 5 \\
\hline Y374A & 0.36 & 0.25 & 6 & 0.54 & 0.26 & 5 & 0.96 & 0.33 & 4 & 0.88 & 0.38 & 5 & 0.23 & 0.07 & 5 \\
\hline V375A & -1.20 & 0.30 & 6 & -2.64 & 0.46 & 5 & -2.38 & 0.46 & 4 & -2.26 & 0.83 & & ND & & \\
\hline M376A & -1.90 & 0.35 & 6 & -2.62 & 0.78 & 4 & -2.78 & 0.65 & 4 & -2.50 & 1.02 & & ND & & \\
\hline
\end{tabular}

${ }^{a}$ For each receptor mutant and ligand, concentration-response data for each pathway were fit with the Black and Leff operational model to derive an affinity-independent measure of efficacy $(\log \tau)$ and functional affinity. These data were corrected for changes in cell surface expression from FACS to yield $\log \tau_{\mathrm{c}}$. Mean, S.E.M., and the individual experimental " $n$ " values are reported. Significance of changes in log $\tau_{\mathrm{c}}$ of each ligand was determined by comparison of mutant receptors to WT values by a one-way ANOVA and Dunnett's post-test ( $p<0.05$ denoted by bold coloured entries. Red, significant decrease $>10$-fold). ND, data were not able to be reliably determined.

RAMP3 in directing the conformation change required for activation of the Gs pathway for this peptide. For hCT, RAMP3 in $\mathrm{AMY}_{3} \mathrm{R}$ appeared to shift the path of change from ECL2 to ECL3, based on the shift in mutational sensitivity between the two receptors (Figure 11B,G), while, in 3D representation, the effect of mutation of $\mathrm{PCT}$ cAMP response was similar across $\mathrm{AMY}_{3} \mathrm{R}$ and CTR (Figure $11 \mathrm{C}, \mathrm{H}$ ).

The largest divergence between the effect of mutation for $\mathrm{AMY}_{3} \mathrm{R}$ and CTR, on peptide-mediated cAMP efficacy, occurred for rAmy, in which, outside of deep pocket residues described above, mutation in ECL3 was generically associated with loss of efficacy for $\mathrm{AMY}_{3} \mathrm{R}$ but had limited effect on CTR (Figure 11D,I). This is consistent with the selective enhancement of rAmy affinity and potency seen at the $\mathrm{AMY}_{3} \mathrm{R}$. While hCGRP potency is also enhanced at the $\mathrm{AMY}_{3} \mathrm{R}$, this effect is less prominent than that induced by RAMP1. ${ }^{20}$ As such, it is perhaps unsurprising that the effect of mutation on hCGRP cAMP efficacy at the $\mathrm{AMY}_{3} \mathrm{R}$ was generally similar to that observed for CTR (Figure 11E,J).

Among the most profound differences in the effect of mutation on $\mathrm{AMY}_{3} \mathrm{R}$ versus CTR was the effect on pERK efficacy (Figure 12). For the CTR, there was minimal observed effect of ECL2 and ECL3 mutation on CTR-mediated pERK
(Figure $12 \mathrm{~F}-\mathrm{J}$ ). In contrast, there was broad loss of pERK efficacy for mutation of $\mathrm{AMY}_{3} \mathrm{R}$ across both ECL2 and ECL3 (Figure 12A-E), supporting a model in which RAMP3 causes a switch in the intracellular transducers engaged by CTR that are linked to the pERK pathway. While there has not been much investigation into the pathways linked to $\mathrm{pERK}$ downstream of $\mathrm{AMY}_{3} \mathrm{R}$ and $\mathrm{CTR}$, the use of pathway inhibitors has implicated PKC, PI3K, and PLC in the phosphorylation of ERK. ${ }^{7}$ While those studies suggested subtle differences in the effect of inhibitors between $A_{M Y} R$ and $\mathrm{CTR}^{7}$ the mechanistic basis for the major changes to sensitivity of mutants for $\mathrm{AMY}_{3} \mathrm{R}$ versus CTR remains to be elucidated. Nonetheless, they suggest that RAMP3 alters conformational propagation at least through ECL2 and ECL3. The exception to this was hCGRP that exhibited a similar pattern of mutational effect for both receptor phenotypes (Figure 12E,J). This lack of effect may reflect the limited induction of hCGRP binding and signaling that occurs with RAMP3, relative to CTR alone, when compared to the phenotypic induction by RAMP $1 .^{20}$ 


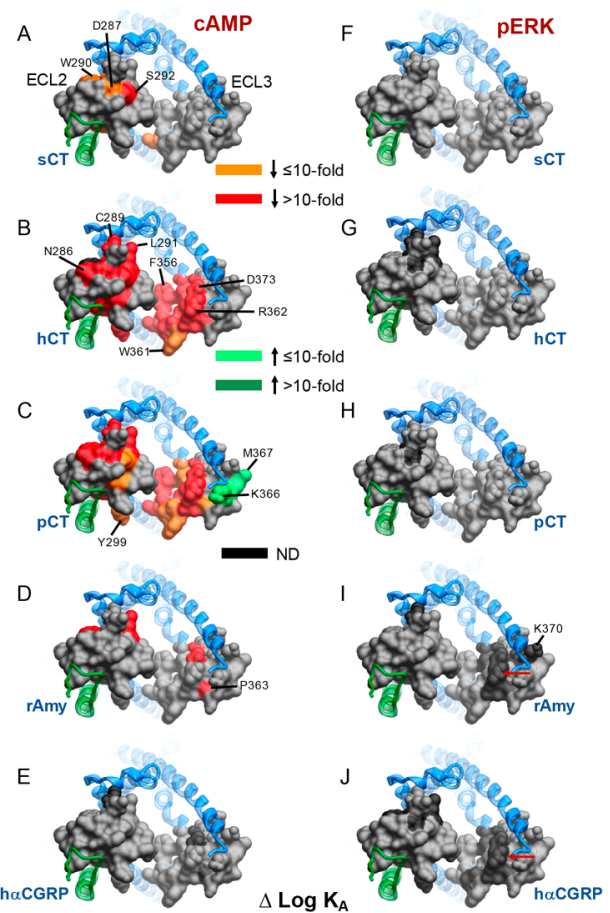

Figure 5. Alanine mutation of ECL2 and ECL3 of $\mathrm{AMY}_{3} \mathrm{R}$ alters functional affinity $\left(\log K_{\mathrm{A}}\right)$ in a peptide- and pathway-specific manner. Functional affinities derived from operational fitting of concentration-response curves in cAMP accumulation (A-E) and pERK $(\mathrm{F}-\mathrm{J})$ are displayed as $\Delta \log K_{\mathrm{A}}$ from wild-type. Illustrated is a top view of the $\mathrm{AMY}_{3} \mathrm{R}$ model with the extracellular surface subject to alanine scanning depicted (combined surface/cpk representation). Mutations that significantly alter peptide functional $\log K_{\mathrm{A}}$ are colored according to the magnitude of effect, with mutated amino acids without significant alteration to $\log K_{\mathrm{A}}$ colored gray. Amino acid mutations for which there was an insufficiently robust functional effect to quantify by operational modeling are depicted in black. The receptor ECD and peptide are not shown for clarity, with the CTR TM bundle in blue ribbon and RAMP3 in green ribbon. Red arrows in panels I and $\mathrm{J}$ indicate residues at the apex of ECL3 that are affected for Amy and CGRP but not CT peptides.

\section{CONCLUSION}

Biased agonism is a key pharmacological behavior of both endogenous GPCR ligands and drugs that target these receptors. Class B GPCRs are important physiological targets that display biased signaling in response to both endogenous and exogenous agonists, although the mechanistic basis for these differential effects is unclear. In this study, we demonstrate that the dynamic nature of CTR ECL2 and ECL3 in propagation of signaling is fundamentally altered when complexed with RAMP3 to form the $\mathrm{AMY}_{3} \mathrm{R}$, despite only having predicted direct interactions with ECL2. Moreover, the work shows that the role of these loops in receptor signaling is highly peptide dependent, illustrating that even subtle changes to peptide sequence may change signaling output downstream of the receptor. The work further supports the allosteric role proposed for RAMPs in altering GPCR function $^{21-25}$ with these changes, as assessed in the current study, extending well beyond the RAMP-CTR interface. While full understanding of these findings will likely require solution of structures of CTR:RAMP3 along with individual agonist peptides and transducer proteins, the current work advances our understanding of peptide control of class B GPCR

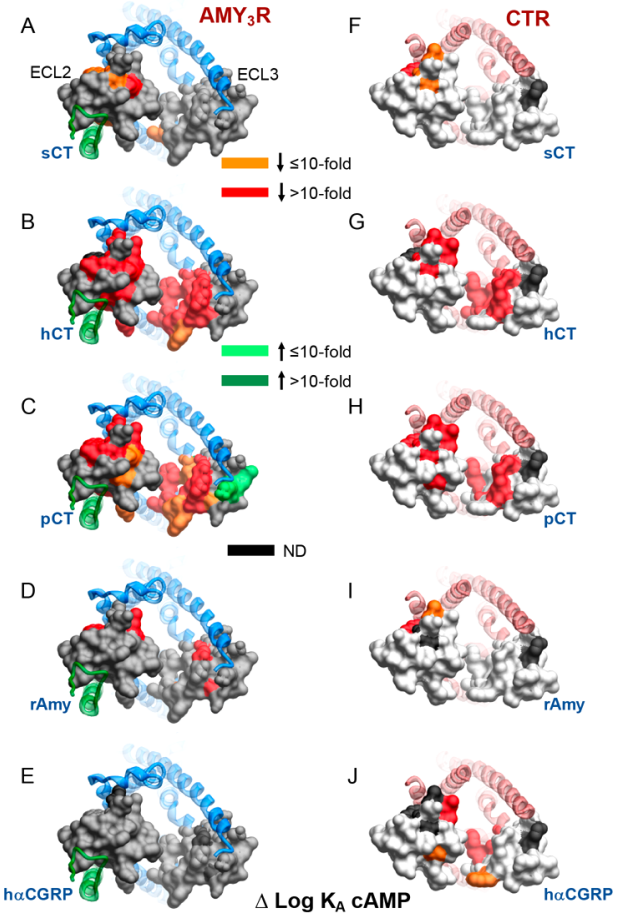

Figure 6. Alanine mutation of ECL2 and ECL3 has distinct effects on $\mathrm{AMY}_{3} \mathrm{R}$ and CTR cAMP functional affinity $\left(\log K_{\mathrm{A}}\right)$. Functional affinities derived from operational fitting of concentration-response curves in cAMP accumulation are displayed as $\Delta \log K_{\mathrm{A}}$ from wildtype for $\mathrm{AMY}_{3} \mathrm{R}(\mathrm{A}-\mathrm{E})$ and $\mathrm{CTR}(\mathrm{F}-\mathrm{J})$. Illustrated are top views of the receptors with the extracellular surface subject to alanine scanning depicted (combined surface/cpk representation). Mutations that significantly alter peptide functional $\log K_{\mathrm{A}}$ are colored according to the magnitude of effect, with mutated amino acids without significant alteration to $\log K_{\mathrm{A}}$ colored gray. Amino acid mutations where there was an insufficiently robust functional effect to quantify by operational modeling are depicted in black. The receptor ECD and peptide are not shown for clarity, with the CTR TM bundle in blue ribbon and RAMP3 in green ribbon in panels A-E, and CTR TM bunding in red ribbon in panels F-J. Data for CTR functional affinity are from Dal Maso et al., 2018. ${ }^{17}$

signaling and the molecular basis for RAMP modulation of receptor function.

\section{METHODS}

Reagents. All peptides were purchased from Mimotopes. Dulbecco's Modified Eagle's Medium (DMEM) was purchased from Invitrogen. Fetal bovine serum (FBS) was purchased from ThermoFisher Scientific. AlphaScreen reagents, Lance cAMP kit, and 384-well Optiplates were purchased from PerkinElmer. SureFire ERK1/2 reagents were obtained from TGR Biosciences and PerkinElmer. Antibodies were purchased from R\&D Systems and ThermoFisher. All other reagents were purchased from Sigma-Aldrich or BDH Merck and were of an analytical grade.

Mutagenesis. Desired mutations were introduced to $\mathrm{N}$ terminally c-Myc tagged human CTR in pENTER 11 (Invitrogen) as previously described, ${ }^{17}$ then LR recombination reactions were conducted to transfer mutated and wild-type (WT) receptor into the pEF5/FRT/Rluc-8/IRES/RAMP3/ Venus destination vector using Gateway Technology (Invitrogen), similar to our previously reported design of 


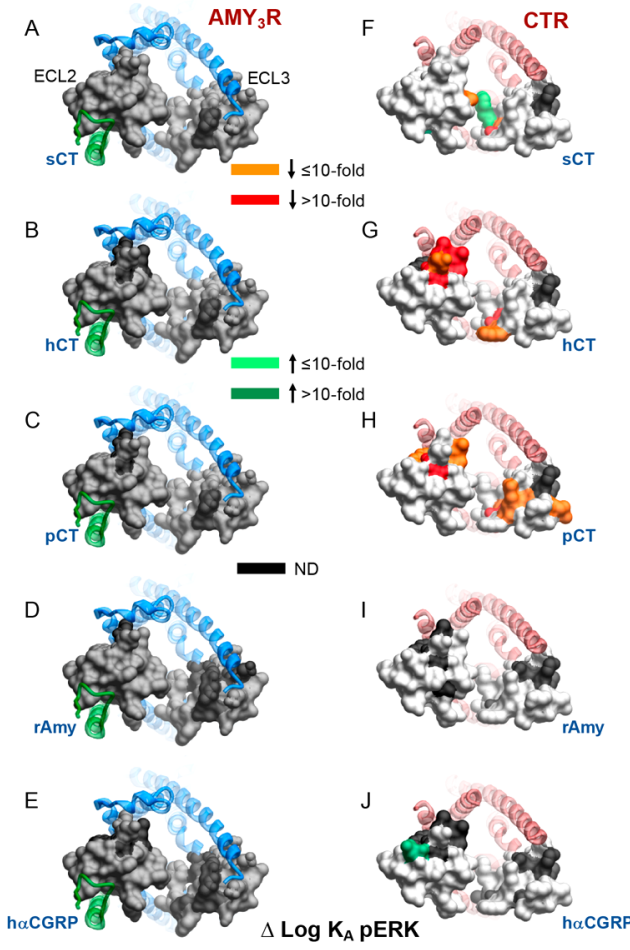

Figure 7. Alanine mutation of ECL2 and ECL3 has distinct effects on $\mathrm{AMY}_{3} \mathrm{R}$ and CTR pERK functional affinity $\left(\log K_{\mathrm{A}}\right)$. Functional affinities derived from operational fitting of concentration-response curves in pERK are displayed as $\Delta \log K_{\mathrm{A}}$ from wild-type for $\mathrm{AMY}_{3} \mathrm{R}$ $(\mathrm{A}-\mathrm{E})$ and CTR $(\mathrm{F}-\mathrm{J})$. Illustrated are top views of the receptors with the extracellular surface subject to alanine scanning depicted (combined surface/cpk representation). Mutations that significantly alter peptide functional $\log K_{\mathrm{A}}$ are colored according to the magnitude of effect, with mutated amino acids without significant alteration to $\log K_{\mathrm{A}}$ colored gray. Amino acid mutations where there was an insufficiently robust functional effect to quantify by operational modeling are depicted in black. The receptor ECD and peptide are not shown for clarity, with the CTR TM bundle in blue ribbon and RAMP3 in green ribbon in A-E, and CTR TM bunding in red ribbon in F-J. Data for CTR functional affinity are from Dal Maso et al., 2018. ${ }^{17}$

bicistronic constructs. ${ }^{26}$ Mutants were confirmed by automated-sequencing.

Stable Cell Line Generation and Cell Culture. The mutant or WT receptor genes were integrated into FlpIn-CV1 cells using Flp-In system (Invitrogen). Stable Flp-In expression cell lines were generated through polyclonal selection and screening and maintained in DMEM supplemented with 5\% (v/v) FBS, $300 \mu \mathrm{g} / \mathrm{mL}$ hygromycin B (Invitrogen) at $37^{\circ} \mathrm{C}$ in $5 \% \mathrm{CO}_{2}$. Independent WT controls were established for each of the ECL2 and ECL3 mutants, as these were created at different times.

Whole Cell Competition Binding Assay. Radioligand competition binding was performed as previously described ${ }^{17}$ on whole cells seeded into 96-well plates and cultured overnight, except that ${ }^{125}$ I-rAmy was used as the radioligand. For homologous competition binding experiments, cells were incubated overnight at $4{ }^{\circ} \mathrm{C}$ with $\sim 100 \mathrm{pM}{ }^{125}$ I-rAmy (specific activity, $2000 \mathrm{Ci} / \mathrm{mmol}$ ) and serial dilutions of non-iodinated rAmy, while heterologous competition was in the presence of increasing concentrations of unlabeled peptide. Non-bound ligand was removed and bound ligand activity was measured using a $\gamma$ counter (Wallac Wizard 1470 Gamma Counter,
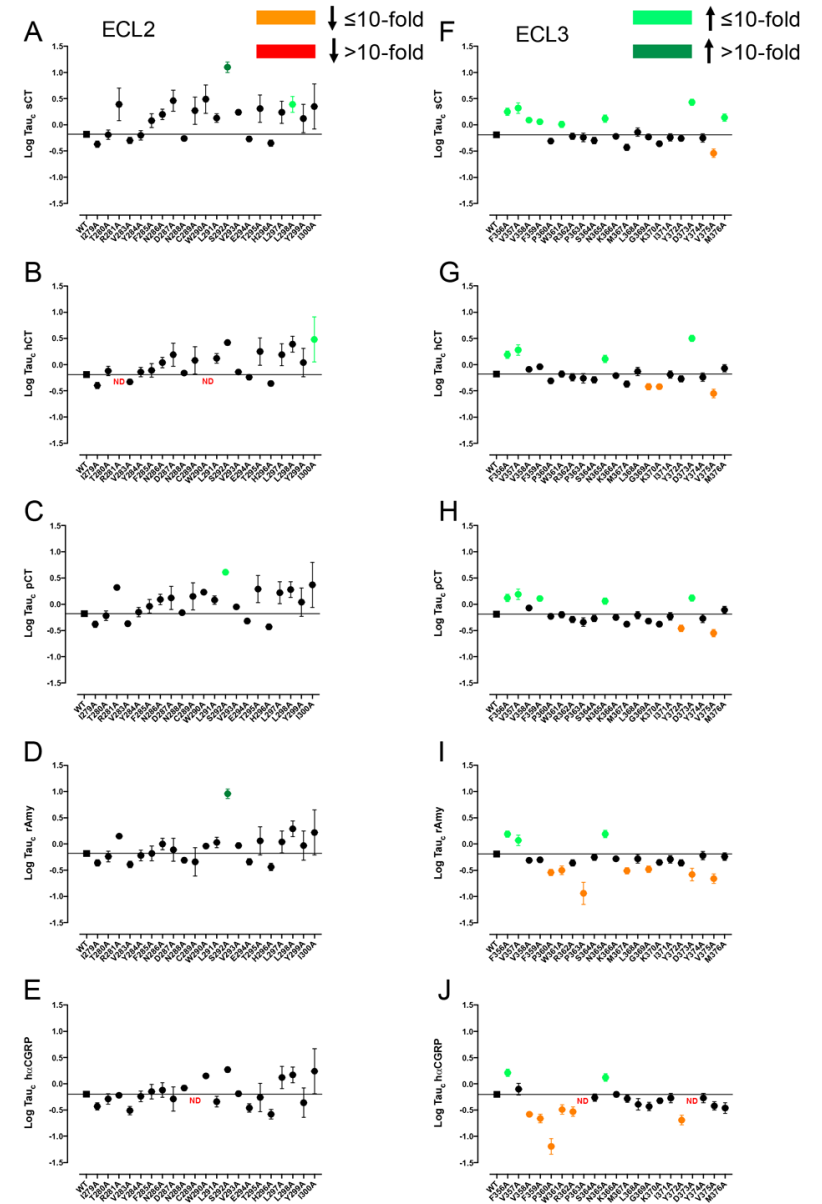

Figure 8. Alanine mutation of ECL2 and ECL3 of $\mathrm{AMY}_{3} \mathrm{R}$ alters cAMP efficacy $\left(\log \tau_{c}\right)$ in a peptide-specific manner. Peptide efficacy $(\log \tau)$ was derived from operational fitting of concentrationresponse curves in cAMP accumulation for alanine mutation of ECL2 (A-E) and ECL3 (F-J), and corrected for cell surface receptor expression to yield $\log \operatorname{tau}_{\mathrm{c}}$. Significance of mutation effect was established by comparison of the WT to the other receptor mutants following one-way ANOVA and Dunnett's post-test with $P<0.05$ accepted as significant. Mutants that significantly reduced $\log \tau_{c}$ are colored orange ( $\leq 10$-fold change), or red ( $>10$-fold change). Mutants that significantly increased $\log \tau_{\mathrm{c}}$ are colored green $(\leq 10$-fold change, light green; $>10$-fold, dark green). Where data were insufficiently robust to derive a reliable value for $\log \tau_{\mathrm{c}}$ no symbol is shown (ND). Quantitative data are reported in Table 4.

PerkinElmer, 78\% counter efficiency). Values were normalized against nonspecific binding, defined by the presence of $1 \mu \mathrm{M}$ of unlabeled rAmy, and total ligand bound radioligand.

Cell Surface Expression Assessment by FACS. Surface expression of $\mathrm{AMY}_{3} \mathrm{R}$ mutants stably expressed in $\mathrm{CV}-1$ cells was quantified by flow cytometry of antibody binding to the cMyc tagged CTR subunit of the receptor using standard methods. Cells were grown in 6-well plates at $\sim 5 \times 10^{5}$ cells per well the day before assay. Cells were harvested in the presence of versene. All staining steps were conducted in ice cold Hank's Balanced Salt Solution (HBSS) with $0.1 \%$ bovine serum albumin (BSA) and $20 \mathrm{mM}$ HEPES (4-(2-hydroxyethyl)-1-piperazineethanesulfonic acid, $\mathrm{pH}$ 7.4). Blocking was conducted in 5\% BSA. Primary antibody staining was performed with $5 \mu \mathrm{g} / \mathrm{mL} 9 \mathrm{E} 10$ (anti-c-Myc) antibody. The secondary antibody was $1 \mu \mathrm{g} / \mathrm{mL}$ goat antimouse AF647 (ThermoFisher). Sytox blue was used for live/dead discrim- 

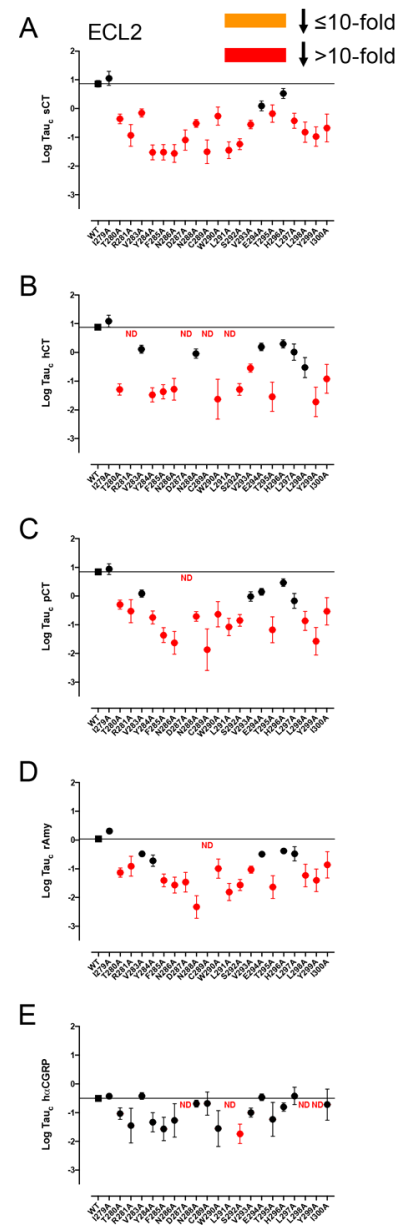
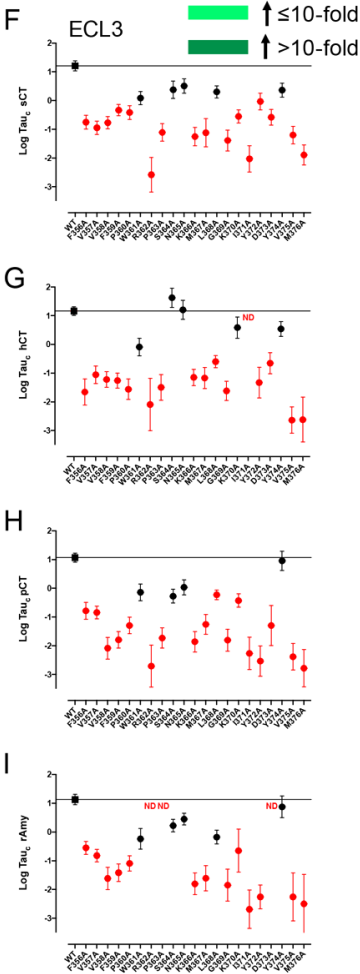

J

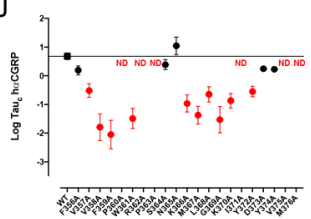

Figure 9. Alanine mutation of ECL2 and ECL3 of $\mathrm{AMY}_{3} \mathrm{R}$ alters pERK efficacy $\left(\log \tau_{c}\right)$ in a peptide-specific manner. Peptide efficacy $(\log \tau)$ was derived from operational fitting of concentrationresponse curves in pERK for alanine mutation of ECL2 (A-E) and ECL3 (F-J), and corrected for cell surface receptor expression to yield $\log \tau_{\mathrm{c}}$. Significance of mutation effect was established by comparison of the wild-type to the other receptor mutants following one-way ANOVA and Dunnett's post-test with $P<0.05$ accepted as significant. Mutants that significantly reduced $\log \tau_{c}$ are colored orange ( $\leq 10$-fold change), or red ( $>10$-fold change). Where data were insufficiently robust to derive a reliable value for $\log \tau_{\mathrm{c}}$ no symbol is shown (ND). Quantitative data are reported in Table 5.

ination. Data were collected on a FACS CantosII (BD Biosciences) with at least 20000 live cells collected per sample. WT stained CTR sample and stained parental CV-1 cells were collected at the beginning and the end of each run. Data were analyzed using FlowJo. The mean AF647 fluorescence intensity from each sample for a particular experiment was normalized against parental (0\%) and WT CTR (100\%) controls.

CAMP Accumulation Assay. Cells $\left(2.5 \times 10^{4}\right.$ cells/well $)$ were seeded into 96-well plates and incubated overnight. Complete media was replaced with phenol red-free DMEM containing $0.5 \mathrm{mM}$ 3-isobutyl-1-methylxanthine (IBMX) and $0.1 \% \mathrm{BSA}$ and preincubated for $30 \mathrm{~min}$. Cells were stimulated with increasing concentrations of ligands for $30 \mathrm{~min}$ in the presence of $0.5 \mathrm{mM} 3$-isobutyl-1-methylxanthine (IBMX). The media was discarded, changed to absolute ethanol and volatilized to dryness at room temperature. Samples were then lysed and intracellular cAMP was detected using the

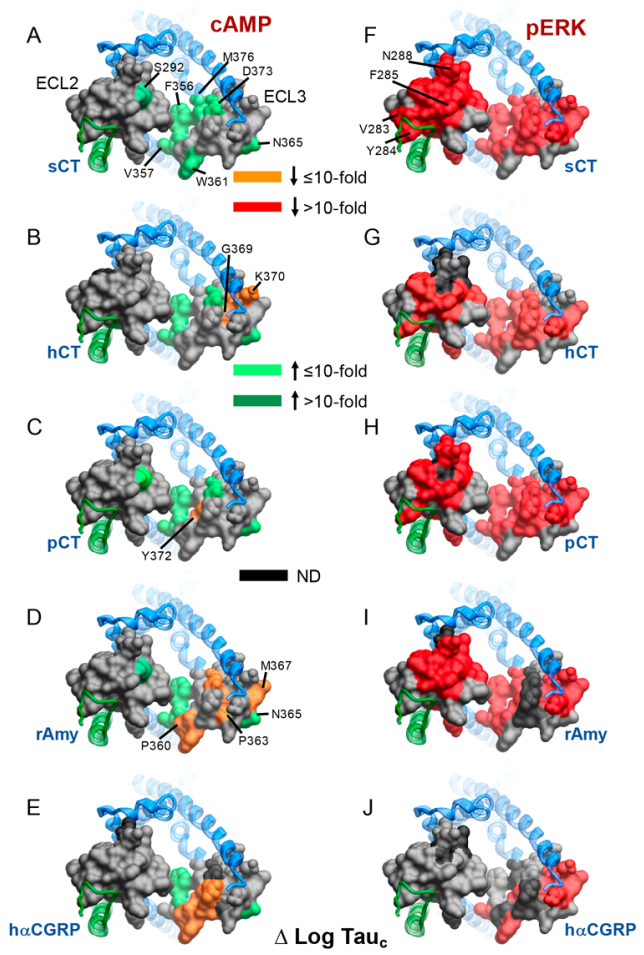

Figure 10. Alanine mutation of ECL2 and ECL3 of $\mathrm{AMY}_{3} \mathrm{R}$ alters peptide efficacy $\left(\log \tau_{c}\right)$ in a pathway-specific manner. Efficacy values derived from operational fitting of concentration-response curves in cAMP accumulation $(\mathrm{A}-\mathrm{E})$ and $\mathrm{pERK}(\mathrm{F}-\mathrm{J})$ are displayed as $\Delta \log \tau_{\mathrm{c}}$ from wild-type. Illustrated is a top view of the $\mathrm{AMY}_{3} \mathrm{R}$ model with the extracellular surface subject to alanine scanning depicted (combined surface/cpk representation). Mutations that significantly alter peptide $\log \tau_{\mathrm{c}}$ are colored according to the magnitude of effect, with mutated amino acids without significant alteration to $\log \tau_{\mathrm{c}}$ colored gray. Amino acid mutations for which there was an insufficiently robust functional effect to quantify by operational modeling are depicted in black. The receptor ECD and peptide are not shown for clarity, with the CTR TM bundle in blue ribbon and RAMP3 in green ribbon.

PerkinElmer Lance kit as previously described. ${ }^{14}$ Data were normalized to the maximal response of each peptide.

ERK1/2 Phosphorylation. Cells $\left(2.5 \times 10^{4}\right.$ cells/well $)$ were seeded into 96-well culture plates and incubated overnight. Initially, pERK1/2 time-course experiments were performed over $30 \mathrm{~min}$ to identify the time point when the pERK $1 / 2$ response is maximal $(6-8 \mathrm{~min})$. Subsequently, this time point was selected to generate concentration response curves for different agonists with ligand addition performed after overnight serum starvation with DMEM. FBS was used as a positive control. pERK1/2 was detected using an AlphaScreen assay as previously described. ${ }^{27}$ Data were normalized to the maximal response elicited by each peptide.

Pharmacological Data Analysis. $\mathrm{IC}_{50}$ and $B_{\max }$ values were estimated from competitive inhibition of ${ }^{125} \mathrm{I}$-rAmy binding using a three-parameter logistic equation [Log(inhibitor versus response)] in Prism (v7 or v8; GraphPad). The concentration of the radioligand was $\leq 5 \%$ of the $K_{\mathrm{D}}$ values. Under these conditions, the $\mathrm{IC}_{50}$ approximates $K_{i}$, and such data are reported as $\log K_{i}$. The Black and Leff operational model of partial agonism ${ }^{19,27}$ was applied to separate effects on pathway-specific efficacy (defined by the value tau, $\tau$ ) from those that modify ligand functional affinity $\left(\log K_{\mathrm{A}}\right)$. Derived $\tau$ values were normalized to experimentally 


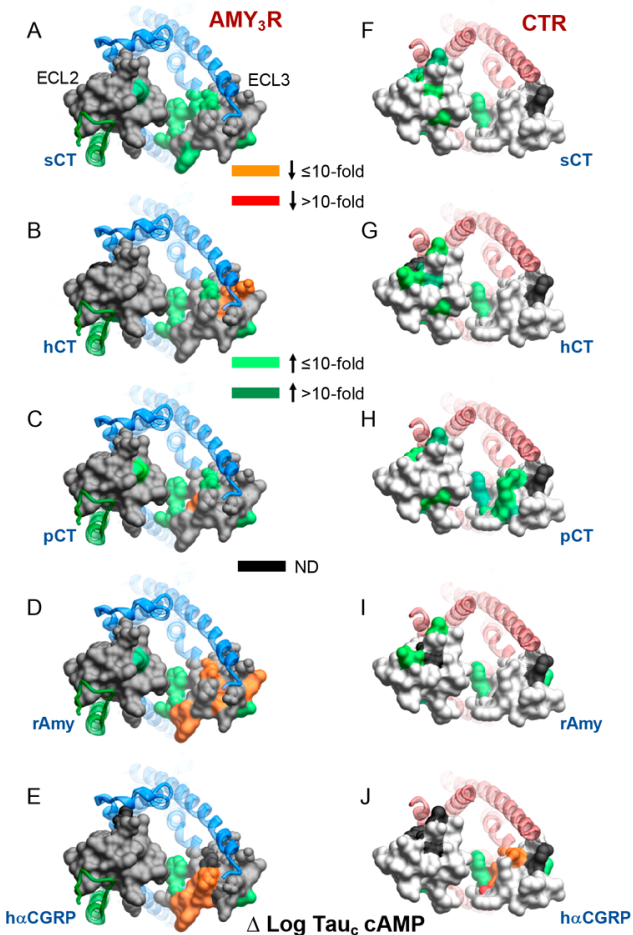

Figure 11. Alanine mutation of ECL2 and ECL3 has distinct effects on cAMP peptide efficacy for $\mathrm{AMY}_{3} \mathrm{R}$ and CTR. Peptide efficacy, derived from operational fitting of concentration-response curves in cAMP accumulation, are displayed as $\Delta \log \tau_{\mathrm{c}}$ from wild-type for $\mathrm{AMY}_{3} \mathrm{R}(\mathrm{A}-\mathrm{E})$ and $\mathrm{CTR}(\mathrm{F}-\mathrm{J})$. Illustrated are top views of the receptors with the extracellular surface subject to alanine scanning depicted (combined surface/cpk representation). Mutations that significantly alter peptide functional $\log \tau_{\mathrm{c}}$ are colored according to the magnitude of effect, with mutated amino acids without significant alteration to $\log \tau_{\mathrm{c}}$ colored gray. Amino acid mutations for which there was an insufficiently robust functional effect to quantify by operational modeling are depicted in black. The receptor ECD and peptide are not shown for clarity, with the CTR TM bundle in blue ribbon and RAMP3 in green ribbon in A-E, and CTR TM bunding in red ribbon in F-J. Data for CTR peptide efficacy are from Dal Maso et al., 2018. ${ }^{17}$

determined levels of cell surface expression to provide a measure of efficacy $(\tau \mathrm{c})$ that is independent of affinity and altered cell surface receptor expression. ${ }^{28} \mathrm{p} K_{i}, \mathrm{p} K_{\mathrm{A}}$ and $\log \tau_{\mathrm{c}}$ values for mutant receptors were statistically compared to those of the respective WT receptor using a one-way analysis of variance (ANOVA) and Dunnett's post-test. Significance was accepted at $P<0.05$.

Computational Methods. System Preparation. The CTR:RAMP3 complex was built using the Modeler comparative modeling program from the full CGRPR ${ }^{15}$ and $\mathrm{CTR}^{16}$ $3.3 \AA$ cryo-EM receptor structures, which included the missing loops, and the $1.76 \AA$ CLR:RAMP2 X-ray crystal structure of the extracellular domain of the adrenomedullin receptor ${ }^{29}$ (PDB codes 6E3Y, 6NIY, and 4RWF, respectively). The disulfide bond between RAMP3 residues Cys 28 and Cys 72 was included. The structure with the best discrete optimized protein energy (DOPE) score ${ }^{30}$ out of 1000 generated models was prepared for molecular dynamics simulation using a combination of python htmd ${ }^{31}$ and tcl (Tool Command Language) scripts. Hydrogen atoms were added using $\mathrm{pdb}$ $2 \mathrm{pqr}^{32}$ the protonation state of titratable side chains was determined using propka ${ }^{33}$ (run at $\mathrm{pH}$ 7) coupled with visual
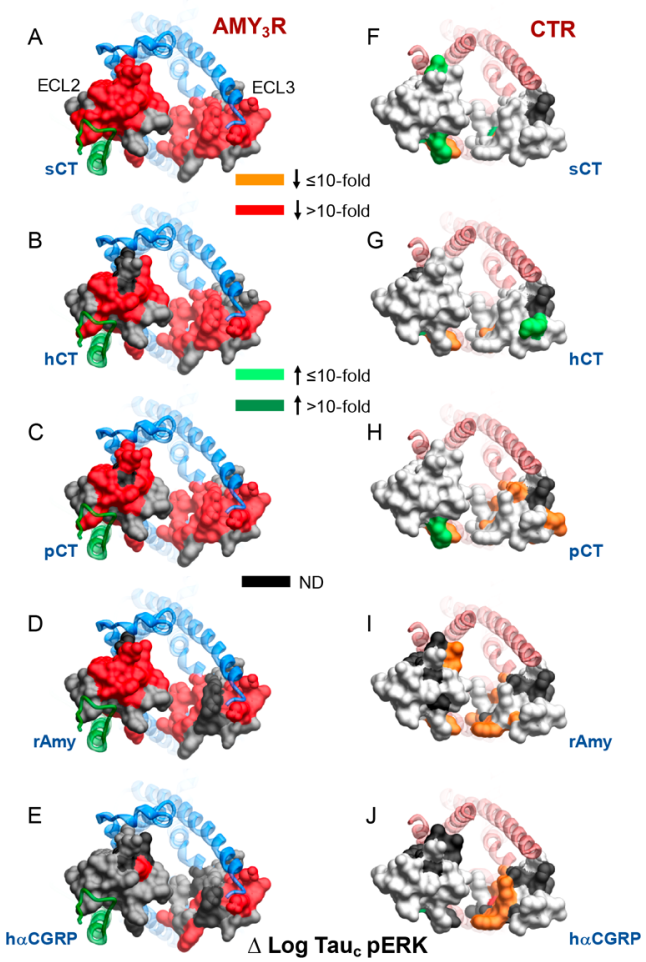

Figure 12. Alanine mutation of ECL2 and ECL3 has distinct effects on pERK peptide efficacy for $\mathrm{AMY}_{3} \mathrm{R}$ and CTR. Peptide efficacy, derived from operational fitting of concentration-response curves in pERK, are displayed as $\Delta \log \tau_{\mathrm{c}}$ from wild-type for $\mathrm{AMY}_{3} \mathrm{R}(\mathrm{A}-\mathrm{E})$ and CTR $(\mathrm{F}-\mathrm{J})$. Illustrated are top views of the receptors with the extracellular surface subject to alanine scanning depicted (combined surface/cpk representation). Mutations that significantly alter peptide functional $\log \tau_{\mathrm{c}}$ are colored according to the magnitude of effect, with mutated amino acids without significant alteration to $\log \tau_{\mathrm{c}}$ colored gray. Amino acid mutations for which there was an insufficiently robust functional effect to quantify by operational modeling are depicted in black. The receptor ECD and peptide are not shown for clarity, with the CTR TM bundle in blue ribbon and RAMP3 in green ribbon in A-E, and CTR TM bundling in red ribbon in F-J. Data for CTR peptide efficacy are from Dal Maso et al., 2018. ${ }^{17}$

inspection. The systems were embedded in a pre-existing 1palmitoyl-2-oleyl-sn-glycerol-3-phospho-choline (POPC) bilayer using an insertion method, ${ }^{34}$ with overlapping lipids removed. The receptor orientation was determined from the Calcitonin receptor-Gs complex (PDB ID: 5UZ7) entry in the OPM database. ${ }^{35}$ TIP3P water molecules ${ }^{36}$ were added to the $106 \AA \times 106 \AA \times 141 \AA$ simulation box using the VMD Solvate plugin version 1.5 (http://www.ks.uiuc.edu/Research/vmd/ plugins/solvate/). Sodium and chloride ions were added to mimic an ionic strength of $0.150 \mathrm{M}$ and to obtain overall charge neutrality, using the VMD Autoionize plugin 1.3 (Autoionize Plugin, Version 1.3. at < http://www.ks.uiuc.edu/ Research/vmd/plugins/autoionize/).

Systems Equilibration and MD Settings. The MD engine $\mathrm{ACEMD}^{37}$ was employed for both the equilibration and productive simulations, which employed the CHARMM36 force field. ${ }^{38}$ Equilibration was achieved in isothermal-isobaric conditions (NPT) using the Langevin thermostat ${ }^{39}$ (target: $300 \mathrm{~K}$ ) with a low damping of $1 \mathrm{ps}^{-1}$ and the Berendsen barostat $^{40}$ (target: $\left.1 \mathrm{~atm}\right)$ over a three-stage procedure using an integration time step of $2 \mathrm{fs}$. First, clashes between protein and lipid atoms were reduced through 2500 conjugate-gradient 
minimization steps followed by a 2 ns long MD simulation with a positional constraint of $1 \mathrm{kcal} \mathrm{mol}^{-1} \AA^{-2}$ on protein and lipid phosphorus atoms. Second, $33 \mathrm{~ns}$ of MD simulation was performed with only the protein atoms constrained. Third, positional constraints were applied only to the protein backbone alpha carbons for a further $35 \mathrm{~ns}$.

A $1 \mu \mathrm{s}$ simulation was run in the canonical ensemble (NVT) at $300 \mathrm{~K}$, using a thermostat damping of $0.1 \mathrm{ps}^{-1}$. The MSHAKE algorithm ${ }^{41}$ was used to constrain the covalent bonds involving hydrogen atoms, enabling a time step of 4 fs. A $9 \AA$ cutoff distance was used for the electrostatic interactions, with a switching function applied beyond $7.5 \AA$; long-range Coulomb interactions were handled using the particle mesh Ewald summation method (PME) ${ }^{42}$ with a mesh spacing to 1.0 A. The mutagenesis results were plotted on the $200 \mathrm{~ns}$ structure, since this was deemed sufficient to remove any strain within the initial structure.

\section{ASSOCIATED CONTENT}

\section{S Supporting Information}

The Supporting Information is available free of charge on the ACS Publications website at DOI: 10.1021/acsptsci.9b00010.

Effect of alanine mutation of ECL2 and ECL3 of $\mathrm{AMY}_{3} \mathrm{R}$ on peptide affinity; competition binding isotherms at WT and mutant $\mathrm{AMY}_{3} \mathrm{R}$; concentration response curves in cAMP accumulation assays and in ERK $1 / 2$ phosphorylation assays at WT and mutant $\mathrm{AMY}_{3} \mathrm{R}$ (PDF)

\section{AUTHOR INFORMATION}

\section{Corresponding Authors}

*E-mail: Patrick.sexton@monash.edu.

*E-mail: denise.wootten@monash.edu.

*E-mail: mwwang@simm.ac.cn.

\section{ORCID}

Debbie L. Hay: 0000-0002-9558-5122

Sebastian G. B. Furness: 0000-0001-8655-8221

Patrick M. Sexton: 0000-0001-8902-2473

\section{Author Contributions}

Contributed to experimental design (E.d.M., D.L.H., D.Y., M.W.W., D.W., P.M.S.); performed experiments (V.P., E.d.M., YZ, C.A.H.); contributed to conceptual development of the project (S.G.B.F., D.L.H., A.C., D.Y., M.-W.W., D.W., P.M.S.); performed molecular modeling (G.D., S.A., C.A.R.); performed pharmacological data analysis (V.P., Y.Z., E.d.M., D.W., P.M.S.); contributed to production of figures (Y.Z., E.d.M., D.W., P.M.S.); provided oversight of the project (M.-W.W., D.W., P.M.S.); drafted the manuscript (Y.Z., P.M.S.).

\section{Author Contributions}

${ }^{\#}$ These authors contributed equally to this work.

\section{Notes}

The authors declare no competing financial interest.

\section{ACKNOWLEDGMENTS}

This work was supported by the National Health and Medical Research Council of Australia (NHMRC) program grant (1055134) and project grants (1061044, 1159006), the National Key R\&D Program of China grant (2018YFA0507000), the National Mega R\&D Program for Drug Discovery grants (2018ZX09711002-002-005 and 2018ZX09735-001), the National Natural Science Foundation of China grants (81573479 and 81773792), Shanghai Science and Technology Development Fund grant (15DZ2291600 and 16ZR1407100), Novo Nordisk-CAS Research Fund grant (NNCAS-2017-1-CC), and the Biotechnology and Biological Sciences Research Council (BBSRC; BB/M006883/1). S.G.B.F. is an ARC Future Fellow. D.W. is a Senior Research Fellow, and A.C. and P.M.S. are Senior Principal Research Fellows, of the NHMRC. D.L.H. is a James Cook Research Fellow of the Royal Society of New Zealand. C.A.R. is a Royal Society Industrial Fellow. S.A. is supported by the Peter Nicholls bequest.

\section{REFERENCES}

(1) Alexander, S. P., Christopoulos, A., Davenport, A. P., Kelly, E., Marrion, N. V., Peters, J. A., Faccenda, E., Harding, S. D., Pawson, A. J., Sharman, J. L., Southan, C., and Davies, J. A. (2017) CGTP Collaborators. The concise guide to pharmacology 2017/18: G protein-coupled receptors. Br. J. Pharmacol. 174 (Suppl. 1), S17S129.

(2) Wootten, D., Christopoulos, A., Marti-Solano, M., Babu, M. M., and Sexton, P. M. (2018) Mechanisms of signalling and biased agonism in G-protein-coupled receptors. Nat. Rev. Mol. Cell Biol. 19, $638-653$.

(3) Wootten, D., Miller, L. J., Koole, C., Christopoulos, A., and Sexton, P. M. (2017) Allostery and Biased Agonism at Class B G Protein-Coupled Receptors. Chem. Rev. 117, 111-138.

(4) Ostrovskaya, A., Findlay, D. M., Sexton, P. M., and Furness, S. G. B. (2017) Calcitonin. Reference Module in Neuroscience and Biobehavioral Psychology, 1-12.

(5) Hay, D. L., Garelja, M. L., Poyner, D. R., and Walker, C. S. (2018) Update on the pharmacology of calcitonin/ CGRP family of peptides: IUPHAR Review 25. Br. J. Pharmacol. 175, 3-17.

(6) Routledge, S. J., Ladds, G., and Poyner, D. R. (2017) The effects of RAMPs upon cell signalling. Mol. Cell. Endocrinol. 449, 12-20.

(7) Morfis, M., Tilakaratne, N., Furness, S. G. B., Christopoulos, G., Werry, T. D., Christopoulos, A., and Sexton, P. M. (2008) Receptor activity modifying proteins differentially modulate the $G$ proteincoupling efficiency of amylin receptors. Endocrinology 149, 54235431.

(8) Hay, D. L., Chen, S., Lutz, T. A., Parkes, D. G., and Roth, J. D. (2015) Amylin: pharmacology, physiology and clinical potential. Pharmacol. Rev. 67, 564-600.

(9) Gydesen, S., Andreassen, K. V., Hjuler, S. T., Hellgren, L. I., Karsdal, M. A., and Henriksen, K. (2017) Optimization of tolerability and efficacy of the novel dual amylin and calcitonin receptor agonist KBP-089 through dose escalation and combination with a GLP-1 analog. Am. J. Physiol Endocrinol Metab 313, E598-E607.

(10) Levin, B. E., and Lutz, T. A. (2017) Amylin and Leptin: CoRegulators of Energy Homeostasis and Neuronal Development. Trends Endocrinol. Metab. 28, 153-164.

(11) Liberini, C. G., Boyle, C. N., Cifani, C., Venniro, M., Hope, B. T., and Lutz, T. A. (2016) Amylin receptor components and the leptin receptor are co-expressed in single rat area postrema neurons. Eur. J. Neurosci 43, 653-661.

(12) Liang, Y.-L., Khoshouei, M., Radjainia, M., Zhang, Y., Glukhova, A., Tarrasch, J., Thal, D. M., Furness, S. G. B., Christopoulos, G., Coudrat, T., Danev, R., Baumeister, W., Miller, L. J., Christopoulos, A., Kobilka, B. K., Wootten, D., Skiniotis, G., and Sexton, P. M. (2017) Phase-plate cryo-EM structure of a class B GPCR-G protein complex. Nature 546, 118-123.

(13) Zhang, Y., Sun, B., Feng, D., Hu, H., Chu, M., Qu, Q., Tarrasch, J. T., Li, S., Kobilka, T. S., Kobilka, B. K., and Skiniotis, G. (2017) Cryo-EM structure of the activated GLP-1 receptor in complex with a G protein. Nature 546, 248-253.

(14) Liang, Y.-L., Khoshouei, M., Glukhova, A., Furness, S. G. B., Zhao, P., Clydesdale, L., Koole, C., Truong, T. T., Thal, D. M., Lei, S., Radjainia, M., Danev, R., Baumeister, W., Wang, M.-W., Miller, L. J., Christopoulos, A., Sexton, P. M., and Wootten, D. (2018) Phase-plate 
cryo-EM structure of a biased agonist-bound human GLP-1 receptorGs complex. Nature 555, 121-125.

(15) Liang, Y.-L., Khoshouei, M., Deganutti, G., Glukhova, A., Koole, C., Peat, T. S., Radjainia, M., Plitzko, J. M., Baumeister, W., Miller, L. J., Hay, D. L., Christopoulos, A., Reynolds, C. A., Wootten, D., and Sexton, P. M. (2018) Cryo-EM structure of the active, Gsprotein complexed, human CGRP receptor. Nature 561, 492-497.

(16) Dal Maso, E., Glukhova, A., Zhu, Y., Garcia-Nafria, J., Tate, C. G., Atanasio, S., Reynolds, C. A., Ramirez-Aportela, E., Carazo, J.-M., Hick, C. A., Furness, S. G. B., Hay, D. L., Liang, Y.-L., Miller, L. J., Christopoulos, A., Wang, M.-W., Wootten, D., and Sexton, P. M. (2019) The molecular control of calcitonin receptor (CTR) signaling. ACS Pharmacol Transl Sci. 2, 31-51.

(17) Dal Maso, E., Zhu, Y., Pham, V., Reynolds, C. A., Deganutti, G., Hick, C. A., Yang, D., Christopoulos, A., Hay, D. L., Wang, M.-W., Sexton, P. M., Furness, S. G. B., and Wootten, D. (2018) Extracellular loops 2 and 3 of the calcitonin receptor selectively modify agonist binding and efficacy. Biochem. Pharmacol. 150, 214-244.

(18) Christopoulos, G., Perry, K. J., Morfis, M., Tilakaratne, N., Gao, Y., Fraser, N. J., Main, M. J., Foord, S. M., and Sexton, P. M. (1999) Multiple amylin receptors arise from receptor-activity modifying protein interaction with the calcitonin receptor gene product. Mol. Pharmacol. 56, 235-242.

(19) Black, J. W., and Leff, P. (1983) Operational models of pharmacological agonism. Proc. R Soc. Lond B Biol. Sci. 220, 141-162. (20) Hay, D. L., Christopoulos, G., Christopoulos, A., Poyner, D. R., and Sexton, P. M. (2005) Pharmacological discrimination of calcitonin receptor:receptor activity-modying protein complexes. Mol. Pharmacol. 67, 1655-1665.

(21) Woolley, M. J., Reynolds, C. A., Simms, J., Walker, C. S., Mobarec, J. C., Garelja, M. L., Conner, A. C., Poyner, D. R., and Hay, D. L. (2017) Receptor activity-modifying protein dependent and independent activation mechanisms in the coupling of calcitonin gene-related peptide and adrenomedullin receptors to Gs. Biochem. Pharmacol. 142, 96-110.

(22) Gingell, J. J., Simms, J., Barwell, J., Poyner, D. R., Watkins, H. A., Pioszak, A. A., Sexton, P. M., and Hay, D. L. (2016) An allosteric role for receptor activity-modifying proteins in defining GPCR pharmacology. Cell Discov 2, 16012.

(23) Watkins, H. A., Chakravarthy, M., Abhayawardana, R. S., Gingell, J. J., Garelja, M., Pardamwar, M., McElhinney, J. M., Lathbridge, A., Constantine, A., Harris, P. W., Yuen, T. Y., Brimble, M. A., Barwell, J., Poyner, D. R., Woolley, M. J., Conner, A. C., Pioszak, A. A., Reynolds, C. A., and Hay, D. L. (2016) Receptor activity-modifying proteins 2 and 3 generate adrenomedullin receptor subtypes with distinct molecular properties. J. Biol. Chem. 291, 11657-11675.

(24) Lee, S. M., Hay, D. L., and Pioszak, A. A. (2016) Calcitonin and amylin receptor peptide interaction mechanisms: Insights into peptide-binding modes and allosteric modulation of the calcitonin receptor by receptor activity-modifying proteins. J. Biol. Chem. 291, $8686-8700$

(25) Booe, J. M., Warner, M. L., Roehrkasse, A. M., Hay, D. L., and Pioszak, A. A. (2018) Probing the Mechanism of receptor activitymodifying protein modulation of GPCR ligand selectivity through rational design of potent adrenomedullin and calcitonin gene-related peptide antagonists. Mol. Pharmacol. 93, 355-367.

(26) Savage, E. E., Wootten, D., Christopoulos, A., Sexton, P. M., and Furness, S. G. (2013) A simple method to generate stable cell lines for the analysis of transient protein-protein interactions. BioTechniques 54, 217-221.

(27) Koole, C., Wootten, D., Simms, J., Valant, C., Sridhar, R. Woodman, O. L., Miller, L. J., Summers, R. J., Christopoulos, A., and Sexton, P. M. (2010) Allosteric ligands of the glucagon-like peptide 1 receptor (GLP-1R) differentially modulate endogenous and exogenous peptide responses in a pathway-selective manner; implications for drug screening. Mol. Pharmacol. 78, 456-465.

(28) Koole, C., Wootten, D., Simms, J., Miller, L. J., Christopoulos, A., and Sexton, P. M. (2012) The second extracellular loop of the human glucagon-like peptide-1 receptor (GLP-1R) has a critical role in GLP-1 peptide binding and receptor activation. J. Biol. Chem. 287, $3642-3648$.

(29) Booe, J. M., Walker, C. S., Barwell, J., Kuteyi, G., Simms, J., Jamaluddin, M. A., Warner, M. L., Bill, R. M., Harris, P. W., Brimble, M. A., Poyner, D. R., Hay, D. L., and Pioszak, A. A. (2015) Structural basis for receptor activity-modifying protein-dependent selective peptide recognition by a G protein-coupled receptor. Mol. Cell 58, $1040-1052$

(30) Shen, M., and Sali, A. (2006) Statistical potential for assessment and prediction of protein structures. Protein Sci. 15, 2507-2524.

(31) Doerr, S., Harvey, M. J., Noé, F., and De Fabritiis, G. (2016) HTMD: High-Throughput Molecular Dynamics for Molecular Discovery. J. Chem. Theory Comput. 12, 1845-1852.

(32) Dolinsky, T. J., Nielsen, J. E., McCammon, J. A., and Baker, N. A. (2004) PDB2PQR: an automated pipeline for the setup of PoissonBoltzmann electrostatics calculations. Nucleic Acids Res. 32, W665W667.

(33) Olsson, M. H. M., Søndergaard, C. R., Rostkowski, M., and Jensen, J. H. (2011) PROPKA3: Consistent treatment of internal and surface residues in empirical pKa predictions. J. Chem. Theory Comput. 7, 525-537.

(34) Sommer, B. (2013) Membrane packing problems: A short review on computational membrane modeling methods and tools. Comput. Struct. Biotechnol. J. 5, No. e201302014.

(35) Lomize, M. A., Lomize, A. L., Pogozheva, I. D., and Mosberg, H. I. (2006) OPM: orientations of proteins in membranes database. Bioinformatics 22, 623-625.

(36) Jorgensen, W. L., Chandrasekhar, J., Madura, J. D., Impey, R. W., and Klein, M. L. (1983) Comparison of simple potential functions for simulating liquid water. J. Chem. Phys. 79, 926-935.

(37) Harvey, M. J., Giupponi, G., and De Fabritiis, G. (2009) ACEMD: Accelerating biomolecular dynamics in the microsecond time scale. J. Chem. Theory Comput. 5, 1632-1639.

(38) Huang, J., and MacKerell, A. D. (2013) CHARMM36 all-atom additive protein force field: validation based on comparison to NMR data. J. Comput. Chem. 34, 2135-2145.

(39) Loncharich, R. J., Brooks, B. R., and Pastor, R. W. (1992) Langevin dynamics of peptides: the frictional dependence of isomerization rates of $\mathrm{N}$-acetylalanyl-N'-methylamide. Biopolymers $32,523-535$.

(40) Berendsen, H. J. C., Postma, J. P. M., van Gunsteren, W. F., DiNola, A., and Haak, J. R. (1984) Molecular dynamics with coupling to an external bath. J. Chem. Phys. 81, 3684-3690.

(41) Kräutler, V., Van Gunsteren, W. F., and Hünenberger, P. H. (2001) A fast SHAKE algorithm to solve distance constraint equations for small molecules in molecular dynamics simulations. $J$. Comput. Chem. 22, 501-508.

(42) Essmann, U., Perera, L., Berkowitz, M. L., Darden, T., Lee, H., and Pedersen, L. G. (1995) A smooth particle mesh Ewald method. J. Chem. Phys. 103, 8577-8593. 